\title{
Políticas y tendencias migratorias en torno al Mediterráneo
}

\section{Jordi Caïs*}

La historia de la región mediterránea está marcada por migraciones frecuentes del Sur al Norte, del Norte al Sur, y en los países de cada uno de los dos lados del litoral entre ellos. Esos movimientos de población juegan un papel importante en el desarrollo político, económico y cultural del área afectando los patrones de interacción y dominación. A pesar de la historia extensa de movimientos de población en la región, la cuestión migratoria no ocupa un lugar predominante en la agenda política internacional hasta la década de los noventa. La migración a gran escala que tiene lugar desde el norte de África a ciertos países europeos desde 1950 a principios de 1970 es tratada como una cuestión económica tanto por los gobiernos de los paises que expelen emigrantes como por los de los que los reciben. Hasta bien entrada la década de los ochenta la cuestión migratoria se confina a burócratas de nivel medio en los Ministerios de Trabajo y Exteriores de los diferentes países. Al inicio de la década de los noventa los gobiernos europeos empiezan a dar importancia al fenómeno migratorio en el Mediterráneo. Ministerios y otras instituciones con potestades en defensa, seguridad interna y políica exterior de los países de Europa Occidental empiezan a encargarse del tema. Por primera vez la cuestión se emplaza en la agenda del grupo de los siete países más industrializados del mundo (G 7). El contexto mediterráneo se convierte en una cuestión central en discusiones de alto nivel y consultas sobre relaciones futuras entre la Comunidad Europea y los países del norte de África.

Cada vez más, una de las dimensiones esenciales que estructura y define al Mediterráneo es la de diferencias y presiones demográficas; no por ellas mismas, sino en términos de movimientos migratorios esperados del Sur hacia el Norte. Las instituciones políticas europeas tienen problemáticas diversas asociadas al fenómeno de la inmigración. En primer lugar, no se ponen de acuerdo en la seriedad del peligro que puede suponer una inmigración incontrolada proveniente de los países del norte de África. Segundo, no queda claro si es un peligro real o sólo percibido; una posibilidad futura que no tiene por qué cumplirse de manera necesaria. Tercero, en el caso de que sea un peligro real, no se define si lo es sólo para algunos miembros de la Unión Europea (los países de la Europa Meridional) o para todos.

Durante el período posterior a la Segunda Guerra Mundial, en el que se produce un reclutamiento elevado de trabajadores foráneos, aparece una cantidad considerable de estudios que tratan los problemas con los que se enfrentan los países de inmigración y las posibles políticas a aplicar ${ }^{1}$. La inmigración no se percibe como problema y se presta poca atención al papel que juegan los países de emigración en todo el proceso. A finales de la década de los ochenta y a principios de los noventa una serie de migraciones masivas producidas a raíz de la caída del muro de Berlín, el éxodo de Albania, o los movimientos de refugiados causados por el conflicto en la antigua Yugoslavia parecen augurar un problema inmigratorio en los países de Europa Occidental. Eso provoca la aceleración del proyecto del Mercado Común y su política asociada de armonización de las leyes de inmigración y asilo en la Comunidad Europea. En 1991 la Asamblea Parlamentaria del Consejo de Europa considera que las diferencias demográficas entre países mediterráneos del Norte y del Sur continuarán incrementándose durante los próxi- 
mos treinta años. Mientras que la población en el sur de Europa se va a mantener bastante estable en las próximas décadas, se prevé que los países de la orilla sur del Mediterráneo pueden doblar su población entre los años 1990 y 2030. Ese diferencial demográfico se produce a la vez que se mantienen las desigualdades económicas. Según predicciones de las Naciones Unidas, los desequilibrios incrementarán al menos hasta el año 2025.

Los gobiernos de los países europeos esperan flujos de migración masivos provenientes de los países del sur y este del Mediterráneo (especialmente de Marruecos, Argelia, Túnez, Egipto y Turquía) ${ }^{2}$ dirigidos a los países del sur de Europa, sobre todo a Portugal, España, Francia, Italia y Grecia ${ }^{3}$. Ese flujo masivo esperado de inmigrantes procedentes de los países del norte de Africa representa un problema para el conjunto de países que conforman la Unión Europea, pero de forma especial para los países que van a ser receptores principales de esos flujos. En el pasado, Portugal, España, Italia y Grecia se caracterizan por ser países que expelen emigrantes. Hoy en día sus pautas de migración se invierten. Pasan de ser países de emigración a países de inmigración ${ }^{4}$. Hasta hace no muchos años, la línea divisoria entre países de origen y países de destino [de flujos migratorios] se situaba en los Pirineos y los Alpes, o en los países paralelos correspondientes. Hoy en día esa línea se ha desplazado hacia el sur, tanto por el origen del grueso de los inmigrantes como por la incorporación al puñado de países de destino de algunos de los países de la Europa meridional. (ARANGo, 1990: 119). El giro en el fenómeno migratorio puede llevar a esos países receptores a adoptar una posición.nueva de países empleadores que se enfrentan al fenómeno de la inmigración ilegal. Es un papel difícil de adoptar sin caer en contradicciones políticas y morales. Es una incógnita de qué manera esos países europeos pueden absorber la inmigración potencial proveniente de las orillas sur y este del Mediterráneo. Hay que tener en cuenta que parte de esa migración procede además de otros países más al sur. La economía sumergida susceptible de incorporar los/as trabajadores inmigrantes en los países del sur de Europa parece insuficiente para compensar las tasas altas de desempleo. Hasta mediados de la década de los ochenta, en los países del Sur de Europa no existe legislación específica sobre controles de entrada, residencia y status laboral de los/as inmigrantes. Un incremento súbito de la inmigración durante la segunda mitad de la década de los ochenta, junto con los compromisos que conlleva formar parte del Mercado Único Europeo y la aplicación del Acuerdo de Schengen fuerzan a los Estados del Sur de Europa a poner en marcha políticas de migración.

En Europa durante los años noventa existe una sensación de vulnerabilidad derivada de la posible ola de inmigración incontrolada del Este y del Sur. Los países que son origen de los flujos de inmigrantes siguen siendo estudiados principalmente a través del prisma de los problemas que esos flujos pueden suponer para Europa Occidental. Se presta poca atención a averiguar las causas reales por las que esos países expelen emigrantes. En Europa, a diferencia de Estados Unidos, donde está arraigada la idea de que los/as inmigrados contribuyen al desarrollo cultural de la sociedad, existe una idea negativa de la inmigración. La llegada masiva de inmigrantes se considera un ataque a la identidad cultural e histórica de los países europeos ${ }^{5}$. En los períodos históricos en los que la inmigración se considera positiva use la considera sólo como una necesidad temporal en las épocas de escasez de mano de obra y expansión económica.. En suma, una forma fácil de llenar huecos, proporcionar la mano de obra necesaria, mantener el desarrollo y reforzar las estructuras que se estaban agrietando por falta de cemento demográfico" (Lrvi-Bacci, 1991: 23). En Europa existe un sentido de justicia social; las actitudes humanitarias son fuertes y sostenidas abiertamente; pero la mentalidad europea no contempla la inmigración como una contribución positiva a largo plazo para el desarrollo de la sociedad. Se la considera un alivio temporal, una necesidad, o incluso un préstamo que debe devolverse ${ }^{6}$.

En la década de los noventa la inmigración de ciudadanos/as es incluso necesaria para mantener el crecimiento total de la población en los países de la UE. Desde mediados de la década de los ochenta, la migración gana importancia como componente del cambio poblacional (véanse los datos en la Tabla 1). En 1995 la contribución de la inmigración al incremento de la población total de la Unión Europea es casi del 75\%. Desde la Segunda Guerra Mundial la migración nunca había tenido una importancia tan alta como componente del crecimiento total de la población. Hay diferencias importantes entre los países de la Unión Europea. Italia y Alemania tendrían un decremento de población sin el influjo de personas provenientes de la migración internacional, mientras que Francia tiene niveles de migración neta que son substancialmente más bajos que el incremento natural de la población. Existe una imagen distorsionada del fenómeno migratorio. No entran más inmigrantes en los países europeos, sino que esos/as inmigrantes representan una proporción mayor del incremento total de la población. En 1995 disminuye ligeramente la inmigración en la UE respecto al quinquenio anterior, pero la fecundidad disminuye bastante más.

El incremento natural de la población disminuye aún más que la inmigración. En 1995, la tasa de fecundidad en la UE alcanza el récord más bajo desde la Guerra: 1,43 niños/as por mujer. En Estados Unidos, por ejemplo, es más de dos niños/as por mujer. Durante los últimos 15 años la fecundidad desciende en la mayoría de países europeos; pero el sur de Europa es el área donde desciende más. Durante siglos, los países europeos meridionales tienen tasas de fecundidad más altas que los del norte, pero hoy en día son más bajas. En los últimos tres lus- 


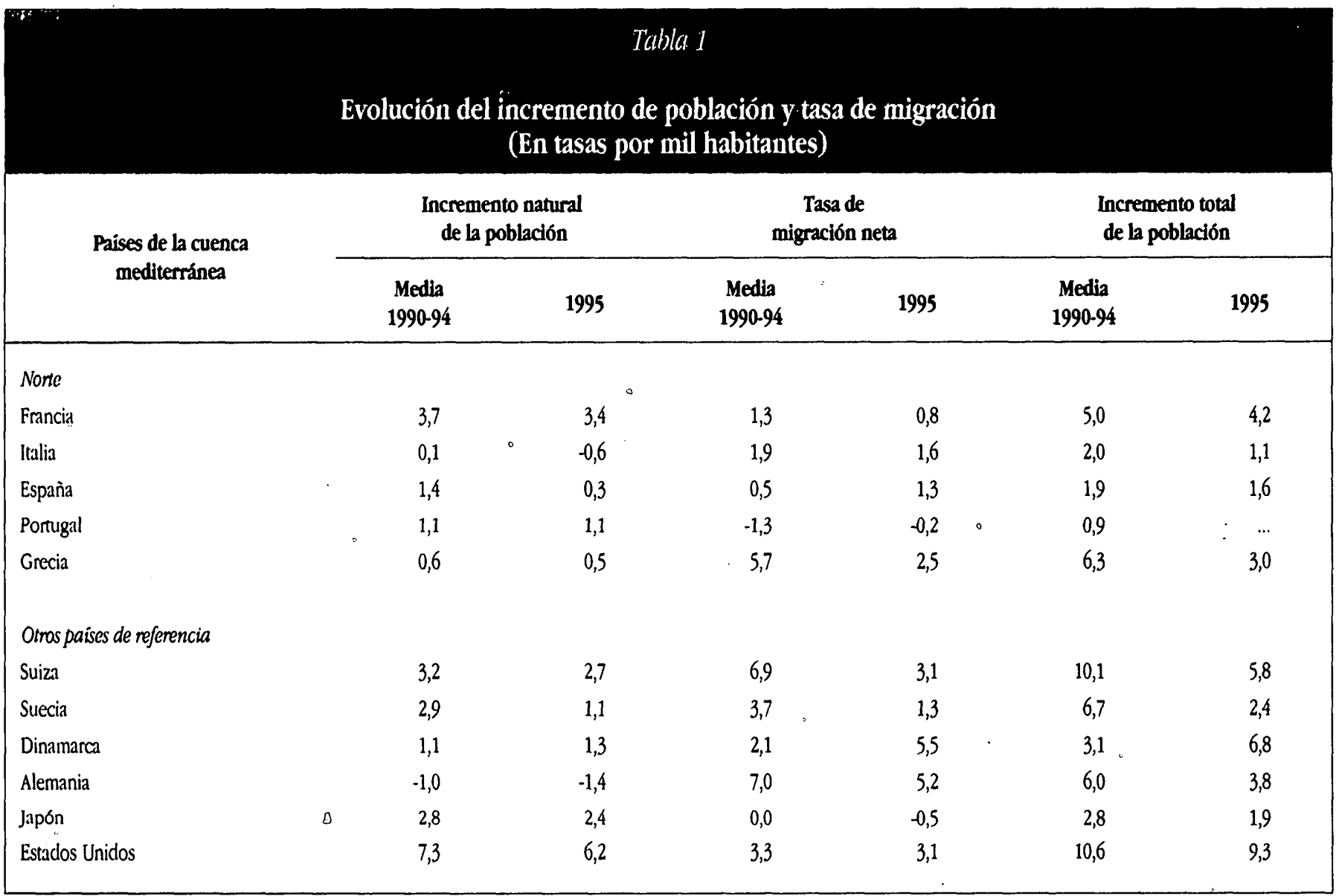

Fuente: Eurostat, Statistics in Focus 1996, vol. 6 (Bruselas: Unión Europea, 1996), p. 3.

Notas: En cada bloque, los países están ordenados según su renta per capita, de más a menos.

tros, descontando a Francia, en todos los países del sur de Europa la fecundidad disminuye más de una tercera parte. En ese período, de los países de la Unión Europea tan sólo Suecia y Dinamarca recuperan algo sus tasas de fecundidad. La inmigración gana importancia relativa aunque el aumento total de población el año 1995 es menor que la media de los años anteriores en todos los países europeos, y también en Estados Unidos y Japón.

En los países mediterráneos, en el lustro que va de 1980 a 1985, la migración neta disminuye en Italia, España y Portugal; esos países pierden población por causa de la migración. Como se observa en la Tabla 2, en esos tres paises meridionales de Europa emigran más personas de las que inmigran. Los flujos de emigrantes se dirigen a los paises de la Unión Europea. En el siguiente quinquenio la migración neta incrementa en todos los países de la Europa meridional excepto en Portugal. Se produce una entrada considerable de inmigrantes procedentes de los países del norte de África; marroquíes en España y tunecinos en Italia. La mayoría de ellos/as son ilegales; pero las campañas de regularización de la situación laboral de los/as inmigrantes promovidas por los gobiernos español e italiano durante la segunda mitad de la década de los ochenta hacen que estadísticamente se note su presencia ${ }^{7}$. Según PRADA (1990: 209), la gran oleada de emigrantes españoles en dirección a los países meridionales de Europa se produce a lo largo de la década de los sesenta. En la década siguiente los flujos de emigración empiezan a disminuir y en la segunda parte de esa década se recupera la mayor parte del contingente de personas que desea retomar. En 1980 vuelve a incrementarse el número de emigrantes españoles como reflejo de la entrada de España en la UE. A pesar de la contabilización de una parte importante de los/as inmigrantes ilegales debido al programa de regularización de 1987, en 1990 España aún pierde población debido a la migración.

En la década de los noventa no hay un patrón definido que explique la evolución de la migración neta en los países del sur de Europa. En Francia se estabiliza la entrada de inmigrantes que ya casi no son laborales sino que obedecen a procesos de reunificación familiar y peticiones de asilo. En Italia y Portugal aumentan los datos de migración neta como consecuencia de la 




Fuentes: Council of Europe, Recent Demographic Developments in Europe 1995 (Estrasburgo: Council of Europe, 1995), p. 24.

Nota: La migración neta se obtiene de la diferencia entre el número de inmigrantes y de emigrantes. En cada bloque, los paises están ordenados según su renta per capita, de más a menos.

entrada de flujos de inmigrantes laborales. En España las cifras de migración neta disminuyen a lo largo de la primera parte de la década de los noventa. Lo que parece claro es que la oleada masiva de inmigrantes procedentes de los países del sur de la cuenca mediterránea en dirección a los del norte no se produce. Portugal sigue perdiendo población por causa de la emigración hasta el año 1993. En los países europeos septentrionales el patrón de migración neta es más claro y con datos siempre más elevados que en los de la Europa meridional. En el quinquenio que va de 1980 a 1985 la migración neta disminuye 0 se mantiene en esos países. A partir de 1989 y en años siguientes, debido principalmente a los cambios políícos derivados de la caída del muro de Berlín, los problemas de Albania y el conflicto en la antigua Yugoslavia, la inmigración en dirección a los países del norte y centro de Europa incrementa de manera significativa. Entre 1985 y 1990 las tasas de migración neta por mil habitantes se multiplican por diez en Alemania, por cuatro en Suiza y por tres en Suecia. Los valores de migración neta bajan en los tres países a partir de 1993, pero siguen manteniendo niveles más altos que los de la primera parte de la década anterior antes de que se produjeran las mi- graciones masivas procedentes de los países del otro lado del "telón de aceron.

En España, en 1980 entran a residir cien mil personas más de las que emigran. España y Portugal recuperan parte de sus emigrantes de la década de los sesenta y setenta (Sopemi, 1993: 15). En 1985 la migración neta parece que disminuye bastante, la recuperación de la mayoría de emigrantes laborales que deciden retornar ya se ha completado y no parece que los flujos de inmigración sean importantes. En la segunda parte de la década de los ochenta parece que los países del sur de Europa pierden población globalmente por causa de la migración (véanse los datos de la Tabla 3). Seguramente esa conclusión es errónea, puesto que los flujos de inmigrantes laborales ilegales procedentes de los países del norte de África que entran en Italia s España ya son relevantes en ese momento pero imposibles de cuantificar (Sopemi, 1993: 15). Los dos países recuperan la tendencia a tener más inmigrantes que emigrantes en el lustro siguiente, aunque posiblemente los flujos de inmigración no sean mucho más importantes que en el lustro anterior, pero en ese momento parte de los inmigrantes ilegales se contabilizan gra- 


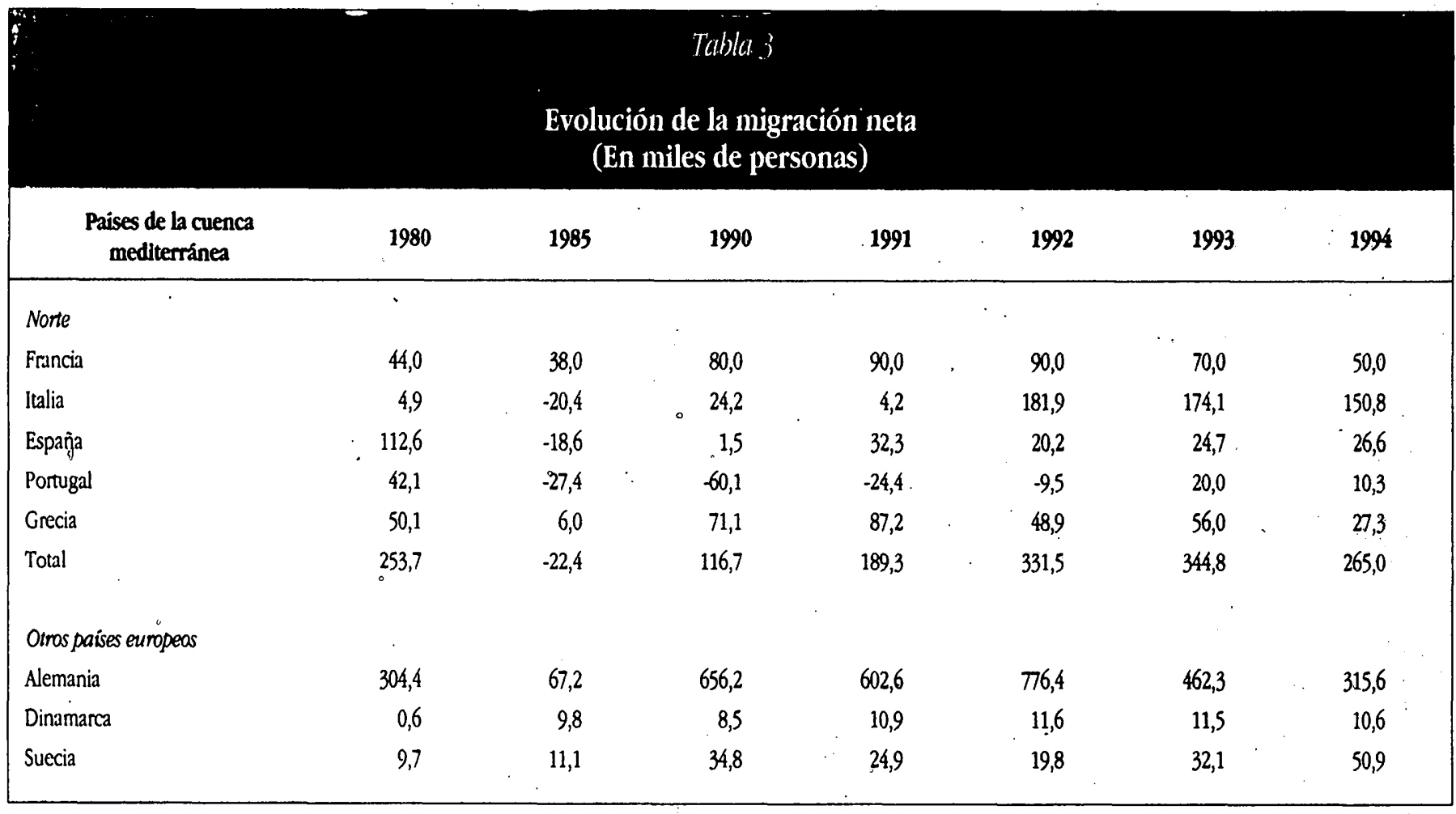

Fuentes: Eurostat; Demographic Statistics 1996 (Bruselas: Unión Europea, 1996), pp. 182-183.

Nota: La migración neta total está formada for el número de inmigrantes (legales) menos el de emigrantes (legales).

cias a los programas de regularización del status laboral que se realizan en los dos países. A partir del año 1992, la migración neta es alta en Italia y en Grecia. España tiene tasas más bajas, estabilizándose en una ganancia de veinte a treinta mil personas al año. Portugal pierde población por causa de la migración hasta el año 1993. Francia, que tradicionalmente es un país que recibe un volumen alto de inmigrantes, a lo largo de los tres quinquenios nunca tiene tasas de migración neta superiores a cien mil personas. El contraste de los países meridionales europeos con Alemania es espectacular; a inicios de la década de los noventa ese país tiene una migración neta de más de seiscientas mil personas, que llega a ser de setecientas mil en 1992.

Los intentos de la mayoría de países europeos de estabilizar el volumen de población inmigrante suelen ser exitosos en el primer lustro de la década de los ochenta. La entrada de inmigrantes se acelera a finales de esa década. «La caída de los regímenes políticos y económicos de los países de Europa Oriental es el factor principal que explica el aumento de los flujos de inmigración a los países de la Unión Europea (HASKEY, 1992: 38). En 1990, la migración neta en la UE es mayor de lo que había sido nunca; por primera vez a lo largo del siglo XX la migración neta es el componente principal del incremento de población (Eurostat, 1993: 6). Ese año en Alemania entran casi 850.000 inmigrantes (véanse los datos en la Tabla 4). El aumento es atribuible tanto a la entrada de inmigrantes laborales - sobre todo de trabajadores cualificados e inmigrantes clandestinos de los países de-la Europa del este- como al aumento del número de peticiones de asilo de personas de los países del Este (CounNSON, 1994: 90-91 ${ }^{8}$. A partir de 1990 aumenta el número de peticiones de asilo debido a un empéoramiento de la situación política y económica de países del Este que se encuentran en el proceso de transición hacia una economía de mercado. En 1991 en Alemania entra más de un cuarto de millón de personas utilizando ese concepto. A lo largo del mismo año, en Italia entran unas 25.000 personas pidiendo asilo. Es una cifra diez veces menor que la de Alemania pero importante puesto que es cinco veces mayor que el volumen de personas asiladas en ese país en años anteriores y es la mitad de. las de Francia que es un país tradicional de inmigración. En España se considera que el sistema de protección de refugiados incentiva la inmigración ilegal. En la resolución sobre migración de marzo de 1991 se propone reducir oficialmente el número de concesiones de asilo o refugio para desincentivar el mal uso. El conflicto de la antigua Yugoslavia, y la Guerra del Golfo, tienen un impacto significativo en 1991 sobre el número de peticiones de asilo en Alemania y Turquía, respectivamente, y también en el número de refugiados políticos y económicos que en Alemania superan las once mil personas (Sopemi, 1993: 13).

A partir de los sucesos políticos y sociales de 1989 que conducen al colapso del bloque de la Europa del este, los países de la Unión Europea temen una invasión migratoria. En el espacio de pocos meses un millón de personas cruzan la barrera 


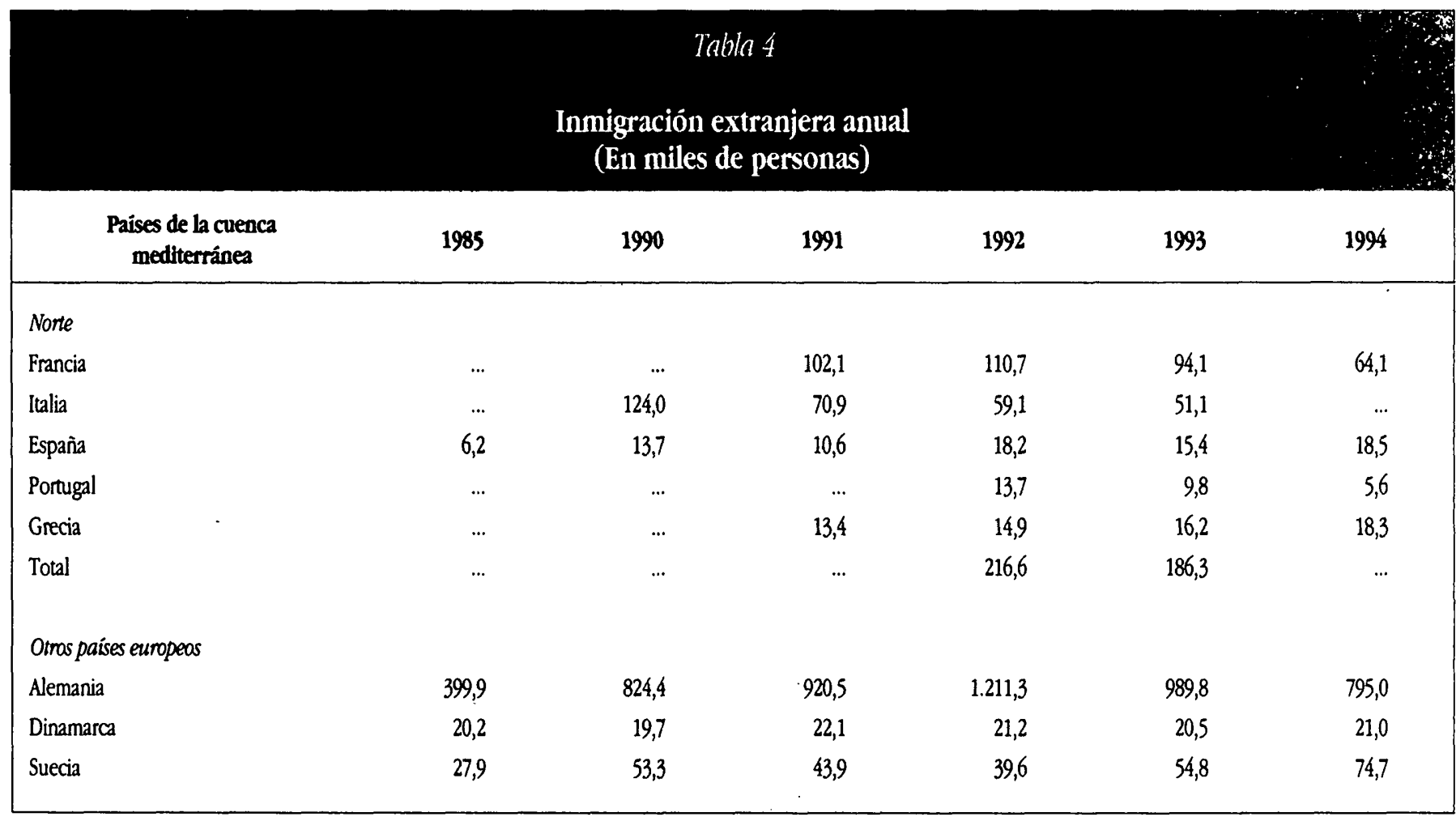

Fuentes: Eurostat, Demograpbic Statistics 1996 (Bruselas: Unión Europea, 1996), pp. 184185.

que durante más de tres décadas separa alas dos Europas». Ello provoca que, a inicios de la década de los noventa, las políticas de los países europeos se dirijan a una regulación más estricta de los flujos inmigratorios y un control más firme de las entradas ilegales. Se crean políticas migratorias conjuntas por parte de los países de Europa occidental aunque la migración procedente del este de Europa parece ser un fenómeno puntual y aislado provocado por un proceso histórico excepcional. Sopemi (1993: 13) afirma que econ la excepción de Alemania y Suecia [...] 1992 y la primera parte de 1993 parecen marcar un punto de inflexión en el proceso de inmigración, que se caracteriza por una disminución de las llegadas de nuevos inmigrantes y de peticiones de asilo, para la que hay varias razones. Un crecimiento económico más lento y el desempleo persistente implica que los países de la OCDE tienen menos necesidad de trabajadores inmigrantes [...] o quizás es una disminución cíclica que posiblemente no tiene un efecto fundamental en la aceleración global de la inmigración internacional. (Sopemi, 1993: 13) ${ }^{9}$. Aunque existe la posibilidad de que las migraciones súbitas y masivas procedentes de los antiguos países comunistas sean un fenómeno aislado y excepcional, en los países de la UE queda una sensación de vulnerabilidad hacia los movimientos de población incontrolados. Es por ello que la Unión Europea gira la cabeza hacia el Sur donde las desigualdades económicas son aun más importantes que con los países del Este. La migración masiva de personas procedentes de los países comunistas de
Europa conlleva que también se preste atención a las desigualdades Norte/Sur que son susceptibles de provocar flujos de migración procedentes de los países africanos y asiáticos de la cuenca mediterránea. Es más el temor a lo que puede suceder en un futuro que el temor a lo que está sucediendo en la actualidad.

A pesar de los temores reflejados por los países miembros de la Comunidad Europea, el análisis de los datos estadísticos demuestra que el boom migratorio de personas procedentes de los países del norte de África hacia los países del sur de Europa no se produce de momento. Según Eurostat, la población total de la Comunidad Europea en 1991 es de 344 millones de personas; 15 millones de las cuales son residentes legales en un Estado miembro de la Comunidad. La tasa de inmigrantes regularizados es del $4,3 \%{ }^{10}$. Los cuatro países de Europa del Sur que reciben más inmigrantes no alcanzan esta cifra. En la Tabla 5 el total de la suma de la población inmigrante regularizada de Italia, España, Portugal y Grecia es de 1,4 a 1,6 millones de personas, y la tasa de inmigrantes regularizados es del 1,4\% del total de los/as residentes. El volumen de inmigrantes residentes en los países de la Europa meridional sigue siendo menor que el volumen residente en la Europa septentrional. El aumento de población en Francia en 1989 es predominantemente debido a un incremento natural y no a la inmigración, en ese año sólo entran unas 50.000 personas inmigradas en el país (Counson, 


\section{Tabla 5}

Población extranjera regularizada en el sur de Europa (En miles de personas)

\begin{tabular}{|llll|}
\hline & \multicolumn{3}{c|}{ Paises de la } \\
Europa meridional & $\begin{array}{c}\text { Eurostat } \\
\text { (1992) }\end{array}$ & $\begin{array}{c}\text { Sopemi } \\
(\mathbf{1 9 9 1 )}\end{array}$ & $\begin{array}{c}\text { Isoplan } \\
\text { (1989) }\end{array}$ \\
\cline { 2 - 4 } & 781,5 & 896,8 & 655,0 \\
Italia & 483,9 & 360,7 (a) & 484,0 \\
España & 106,8 & 114,0 & 95,0 \\
Portugal & 229,1 (b) & 70,0 (c) & $200,0(\mathrm{~b})$ \\
Grecia & $1.602,3$ & $1.441,5$ & $1.434,0$ \\
\hline Total & & & \\
\hline
\end{tabular}

Fuentes: Eurostat. Migration Statistics 1994 (Bruselas: Comunidad Europea, 1993), p. 109. Sopemi, Trends in International Migration: Continuous Reporting System of Migration (Paris OECD, 1993), pp. 81, 195-197.

Isoplan: Institute for Development Research. Economic and Social Planning (Saarbrücken/ Bonn: Isoplan, 1989)

Notas: Se analiza Portugal, España, Italia y Grecia porque son paises que invierten sus patrones de migración. Pasan de ser países de emigración a paises de inmigración

(a) Según el .Ministerio de Asuntos Sociales. Anuario de Migraciones 1994 (Madrid: Ministerio de Asuntos Sociales, 1994), en diciembre de 1992 el número de immigrantes extranjeros regularizados/as es de 393.100 .

(b) Incluye griegos de nacionalidad foránea.

(c) Año 1990.

1994: 90). El año siguiente el número de inmigrantes se duplica, pero en 1994 ya vuelve a acercarse a 50.000 personas. A diferencia de Alemania, el incremento del volumen de inmigración en Francia es debido más al fenómeno de la reunificación familiar y a los nacimientos de hijos e hijas de inmigrantes que no al aumento de los/as inmigrantes laborales o de las personas que entran pidiendo asilo. “En Francia, las políticas humanitarias de reunificación familiar permiten [...] que muchos inmigrantes que hasta ese momento trabajan y viven solos se conviertan en el soporte de una familia entera [...] La tendencia a la reunificación familiar se refuerza por las restricciones crecientes de entrada. Cuando los/as inmigrantes viajan a su país de origen a visitar sus familias encuentran próblemas en reentrar en el país de inmigración para trabajar ótra vez [...] También es importante destacar que las tasas de fecundidad de las minorías étnicas siempre exceden las de las poblaciones nativas" (HASKEY, 1992: 38). Sorprende que los gobiernos europeos se alarmen y actúen de manera contundente y rápida ante un problema que de momento no existe, y que es discutible que se produzca en el futuro. Eso es debido a que, a pesar de la importancia política que se le da al tema, el fenómeno migratorio internacional en la cuenca del Mediterráneo está poco estudiado. Se realizan políticas conjuntas para reaccionar a la inmigración de los países del Este que se extrapolan a la posible inmigración procedente del Sur. Pero no es posible generalizar el fenómeno migratorio; el sistema migratorio que conforman los países africanos y asiáticos de la cuenca mediterránea con Europa es diferente del que conforman los de Europa del este. Laposible migración de una orilla a la otra del Mediterráneo es un tema políticamente importante, pero se observa una carencia sorprendente de datos y estudios al respecto. Una revista tan importante como International Migration Review publica en los últimos siete años pocos artículos referentes a las presiones demográficas y posibles migraciones en la cuenca del Mediterráneo ${ }^{11}$.

La población inmigrante crece en número a mayor velocidad en el sur que en el norte de Europa. La población extranjera que reside legalmente en los cuatro países de Europa meridional que cambian sus tendencias de migración a partir de la década de los ochenta (Italia, España, Grecia y Portugal) aumenta en 600.000 personas entre los años 1985 y 1991. Ese incremento representa una media anual de crecimiento del volumen de población inmigrante del 29\%. En toda la Comunidad Europea la media anual de crecimiento para ese mismo período es del 6\% (véase la Tabla 6). En valores absolutos entran más personas inmigradas en los países europeos septentrionales que en los meridionales. En los países tradicionales de inmigración la base sobre la que se calculan los incrementos es mayor, por lo que a veces la comparación de porcentajes de incremento entre países europeos del norte y del sur puede ser engañosa. En realidad, siguen entrando más personas en los países tradicionales de inmigración que en los nuevos países de inmigración del sur de Europa; aunque en esos últimos el fenómeno al ser nuevo es posiblemente más difícil de asumir. Según Eurostat (1993: 6-7), en los cuatro países de la Europa mediterránea que invierten sus patrones de migración residen algo más de 400.000 inmigrantes legales en 1986 que representan algo más del 5\% del total de inmigrantes en los países de la Unión Europea. En 1991 el número de inmigrantes en esos cuatro países ya es de un millón que es el 10\% del total de inmigrantes de la UE. El número de personas inmigradas en esos países se incrementa en 600.000 , pero en el resto de países de la UE el aumento és de más de dos millones. En Alemania, la población extranjera aumenta en casi un millón de personas entre 1988 y 1990 como resultado de nacimientos de madres extranjeras (especialmente de mujeres turcas que ya viven en Alemania), del aumento de las personas que piden asilo, y de la entrada de trabajadores inmigrantes especialmente de Yugoslavia, Turquía y Rumania. El volumen de inmigración sigue siendo mayor en la Europa septentrional que en la meridional donde el fenómeno es nuevo y el porcentaje de inmigrantes del total de la población es bastante más bajo que en los países del centro y norte de Europa. En Italia la proporción de población foránea respecto al total es algo mayor que en los otros tres países nuevos de inmigración. La población extranjera en Italia se incrementa en un $85 \%$ durante el período $1985 / 1990$. Gran parte de 


\begin{tabular}{|ccc|}
\hline \multicolumn{2}{|c|}{ Tabla 6} \\
Población inmigrante (legal) en el sur de Europa \\
(En miles de personas)
\end{tabular}

Fuentes: Eurostat. Rapid Reports: Population and Social Conditions: 1993 (Luxemburgo: Co munidad Europea, 1993), pp. 6-7.

Notas: Se analiza Portugal, España, Italia y Grecia porque son paises que invierten sus patrones de migración. Pasan de ser paises de emigración a paises de inmigración

ese crecimiento deriva de las campañas de regularización que se realizan para insertar a trabajadores extranjeros indocumentados. España toma también esa decisión introduciendo leyes para regularizar el status de los/as inmigrantes ilegales.

A pesar de que a lo largo de la década de los ochenta el volumen de población extranjera aumenta un 160\% en Italia y un 80\% en España, en 1990 la población extranjera representa aún una proporción baja de la población total que reside en esos dos países (un 1,5\% en Italia y un 1\% en España, tal como se observa en la Tabla 7). Los flujos de inmigrantes laborales que entran en Italia y España en la segunda parte de la década de los ochenta son significativos, pero de ninguna manera comparables en tamaño a los que se dirigen a los países del norte de Europa en la década de los sesenta y la de los setenta debido a la demanda de mano de obra. También son menores en tamaño que los flujos de inmigrantes de los países de la antigua Europa comunista que se dirigen a Europa central y del norte a partir de 1989. En Grecia entre 1985 y 1990 el volumen de inmigración se incrementa en más del 275\%. Ese país recibe poca inmigración procedente de los países del norte de África, pero mucha procedente de los países balcánicos, especialmente de Albania y de las antiguas repúblicas yugoslavas. Portugal manifiesta un incremento moderado de migración entre 1985 y 1990; comparado con el del resto de países occidentales de la Europa mediterránea es el país donde el fenómeno migratorio es menos importante. En Francia y Bélgica, que son países que absorben inmigrantes de manera continuada desde hace varias décadas y donde de cada cien personas respectivamente seis y nueve son foráneas, el volumen de población extranjera se mantiene estable en la década de los ochenta. En otros paises con componentes elevados de personas extranjeras, la cifra de extranjeros/as aumenta durante la década de los ochenta. Es el caso de Alemania, Suiza o Suecia donde el volumen de personas extranjeras se incrementa alrededor de un 20\%. El aumento se produce en la segunda parte de la década de los ochenta a raíz de los conflictos que conducen a la destrucción del sistema económico y políticos de la Europa del este. A lo largo de la primera parte de la década el porcentaje de extranjeros/as se mantiene estable en la mayoría de países del centro y el norte de Europa e incluso disminuye en Alemania y Suecia.

Sacar conclusiones de datos estadísticos sobre inmigración es una tarea compleja puesto que hay numerosos canales de inmigración y diversas categorías de inmigrantes. Además, las definiciones y. sistemas de recolección de datos varían considerablemente de un país a otro ${ }^{12}$. Las Naciones Unidas definen como ainmigrante a cualquier persona que pretende estar más de un año en otro país. Muchos países no se adhieren a esa afirmación cuando realizan las estadísticas nacionales. Las comparaciones de datos entre países a veces son complicadas. Posiblemente, la definición más obvia es que el/la inmigrante debe haber nacido en el extranjero. Es un criterio simple que depende de una característica demográfica que no cambia a lo largo del tiempo. Pocos países europeos utilizan ese concepto para definir a las personas inmigrantes. Algunos incluyen alguna pregunta sobre el país de nacimiento en los censos; pero debido a que ésos acostumbran a efectuarse una vez cada diez años son una fuente de datos que no es adecuada para medir cambios o tendencias acelerados o hacer comparaciones entre países. Para solventar esos problemas, los países europeos acostumbran a recolectar datos y analizar las estadísticas de inmigración a partir de la característica "nacionalidad" de la persona. Distinguen extranjeros/as de nacionales según sea el país del que son ciudadanos/as. La mayoría de países europeos mantienen registros de población de los cuales se pueden obtener esos datos. En muchos países europeos la información sobre migración también es recolectada como producto derivado de procesos legales y administrativos que son creados originalmente con el propósito de obtener la identidad y número de inmigrantes para desarrollar políticas de inmigración. En los países europeos, la nacionalidad es el criterio más importante para permitir o no la entrada de inmigrantes.

El análisis no debe limitarse a la inmigración legal ${ }^{13}$. Para tener una visión clara del fenómeno migratorio en el sur de Europa es necesario examinar los datos relativos a población residente extranjera en estado de irregularidad (también llamada ilegal). Es difícil realizar cálculos referentes a la inmigración irregular. Debido a la variedad de situaciones de ilegalidad entre la población inmigrante, la dimensión cuantitativa de la inmigración irregular sólo puede ser estimada de forma precaria. 




Fuente: Sopemi, Trends in Intermational Migration: Continuous Reporting System of Migration (Paris: OECD, 1992), pp. 179-205.

Eurostat, Rapid Repons: Poptlation and Social Conditions 1993 (Luxemburgo: Comunidad Europea, 1993), pp. 6-7.

Notas: En cada bloque, los paises están ordenados según su renta per capita, de más a menos.

La información existente sobre inmigración irregular en el sur de Europa se basa en: (a) estudios de organizaciones internacionales $^{14}$, (b) estudios de caso a nivel nacional y local que utilizan información que proviene de trabajadores sociales y otros expertos ${ }^{15}, y(c)$ información obtenida utilizando datos procedentes de procesos de regularización de inmigrantes ilegales ${ }^{16}$. En los países del sur de Europa la irregularidad es la característica básica de la inmigración. La parte anvisible e de la población extranjera es casi tan grande como la parte "visible". La Tabla 8 compara estimaciones del número de inmigrantes irregulares en los cuatro países del sur de Europa que pasan de ser países de emigración a países que atraen inmigración en las dos últimas décadas del siglo XX. Aunque, según Coluinson (1994: 86), ninguna estimación del volumen de inmigrantes ilegales es exacta, los datos que proporcionan las fuentes diversas son bastante homogéneos. Se estima que la mitad de los tres millones de extranjeros que residen en los países de Europa meridional están en situación de irregularidad. La inmigración ilegal es un fenómeno más importante en Italia y España que en Portugal o Grecia. Las estimaciones del número de inmigrantes ilegales en Italia son altas, en algunos casos se acercan al millón de personas. Se considera que la inmigración ilegal es menor en España; las cifras no sobrepasan las trescientas mil personas ${ }^{17}$. En 1990 un estudio del Consejo de Europa estima que hay entre 1,3 millones y 1,5 millones de personas extranjeras indocumentadas o en situación de irregularidad en los nuevos países de inmigración del sur de Europa. Teniendo en cuenta esas cifras el total de personas extranjeras residentes en esos cuatro países de la Europa meridional es de casi tres millones de personas. Las cifras que ofrece la ILO en 1992 son más moderadas: 650.000 inmigrantes indocumentados en Alemania, 600.000 en Italia, 300.000 en España y 200.000 en Francia para un total de dos millones y medio de inmigrantes ilegales en toda la UE. De las cifras ofrecidas por la ILO se deduce que el fenómeno de la inmigración ilegal es proporcionalmente más importante en los países nuevos de inmigración que en los tradicionales. BODEGA y otros/as argumentan que "el carácter de España como país de inmigración sólo es evidente cuando se considera el número de personas que viven de manera ilegal en el país" (1995: 805). Los tres millones de personas extranjeras residentes en Italia, España, Portugal y Grecia, contando las cifras oficiales de inmigrantes legales y las estimaciones más elevadas del número de inmigrantes ilegales (que son las del Consejo de Europa), representan el 2,5\% del total de la población de los cuatro países. Es una cifra bastante menor que $4,3 \%$, que es la tasa media de inmigrantes legales residentes en los países de la Unión Europea según Eurostat. 


\section{Tabla 8}

$+$

Estimaciones del nuimero de residentes extranjeros

ilegales en el sur de Europa

(En miles de personas)

\begin{tabular}{|lcccr|}
\hline $\begin{array}{c}\text { Paises de la } \\
\text { Europa meridional }\end{array}$ & $\begin{array}{c}\text { Eurostat } \\
(\mathbf{1 9 9 2 )}\end{array}$ & $\begin{array}{c}\text { Sopemi } \\
(\mathbf{1 9 9 1 )}\end{array}$ & $\begin{array}{c}\text { Sopemi } \\
(\mathbf{1 9 9 1 )}\end{array}$ & $\begin{array}{c}\text { Isoplan } \\
(\mathbf{1 9 8 9 )}\end{array}$ \\
\hline Italia & 850 & 600 & $\ldots$ & $\ldots$. \\
España & 294 & 300 & $\ldots$ & $\begin{array}{r}294(\mathrm{IOE})^{(\mathrm{a})} \\
\end{array}$ \\
& & & & $\begin{array}{r}295(\mathrm{PASS})^{(\mathrm{b})} \\
132(\mathrm{AIE})^{(\mathrm{c})}\end{array}$ \\
Portugal & 60 & $\ldots$ & $\ldots$ & $\ldots$ \\
Grecia & 70 & $\ldots$ & $\ldots$ & $\ldots$ \\
\hline Total & 1.274 & $\ldots$ & $1.300-1.500$ & \\
\hline
\end{tabular}

Fuentes: United Nations: Economic Commission for Europe, Economic Survey of Europe in 1991-1992 (Nueva York: United Nations, 1992).

International Labor Organization, World Labour Report 5: Human Rights at Work: Employmen Labour Relations, Social Protection and Working Conditions. Statistical Appendix (Ginebra ILO, 1992).

Council of Europe, Report of the New Countries of Immigration. Document 6211, Parliamentary Assembly (Luxemburgo: Council of Europe, 1990).

Notas: Se analiza Portugal, España, Italia y Grecia porque son paises que invierten sus patrones de migración. Pasan de ser países de emigración a países de inmigración.

(a) Colectivo IOE. Spain's illegal immigrants. pp. 117-139 en T. Hammar et al. European Immigration Policy (Londres: Pergamon Press, 1990).

(b) PASS, Asesoría de Programas de Servicios Sociales. Mapa de inmigración extranjera en situación irregular (Madrid: Ministerio de Trabajo y Seguridad Social, 1992).

(c) Antonio IzQuERDo. La inmigración en España 1980-1990 (Madrid, Ministerio de Trabajo y Seguridad Social, 1992).

Existe un número elevado de formas de irregularidad que dificultan la realización de estimaciones sobre el volumen de la inmigración en los países. El contingente de inmigración ilegal más obvio está formado por las personas que entran en el país huésped evitando los controles de fronteras o utilizando documentación falsa. También están las situaciones de irregularidad derivadas de formas legales de migración, tales como los/as inmigrantes que prolongan su estancia o trabajo un tiempo superior al del período permitido, y los que aun estando en posesión de un permiso de residencia trabajan en un sector diferente del que deberían trabajar según su autorización ${ }^{18}$. Es el caso también de estudiantes que trabajan sin un permiso, o de la esposa de un trabajador inmigrante que entra de forma legal pero que ejerce una actividad de trabajo de manera ilegal. Debido a la propia naturaleza del dato, la estimación del número de inmigrantes ilegales en un país es complicada aunque aún lo es más averiguar las nacionalidades de esos/as inmigrantes ilegales.

Una manera de aproximar los datos de inmigración irregular es a partir del número de peticiones de legalización de residencia en los pocos países que ofrecen esos programas. En España o Italia se realizan programas masivos de regularización durante la segunda parte de la década de los ochenta y la primera de los noventa. Hasta bien entrada esa década, ni en Italia ni en España existen controles de inmigración o legislación específica concerniente a residencia o status laboral de los/as inmigrantes. El incremento súbito de la inmigración a finales de los ochenta, junto con el proyecto del mercado común y la firma del Acuerdo de Schengen, fuerza a esos países a introducir políticas de inmigración de manera acelerada. Son políticas duales que, por un lado, introducen controles de inmigración parecidos a los que operan en la mayoría de países de Europa Occidental; y por otro lado, incentivan la regularización e integración de los/as inmigrantes ilegales que en esos momentos ya residen y trabajan dentro del país. La política italiana más importante en inmigración es la Ley 943 aprobada en diciembre de 1986. Esa ley impone sanciones a cualquier persona que emplee de manera irregular a inmigrantes u opere como intermediario/a en el movimiento clandestino de trabajadores/as foráneos. La legislacion se completa en febrero de 1990 con la Ley 39, conocida como Ley Martinelli, que regula las condiciones de entrada y el status de legalidad de los/as inmigrantes no comunitarios. Con esa ley se somete a los flujos de inmigrantes a controles más estrictos. A partir de ese momento se requiere visado para entrar en Italia desde países del norte de África que son considerados la fuente principal de inmigrantes ilegales. Además, el volumen de inmigrantes con contrato laboral queda sujeto a un programa anual controlado por el gobierno que toma decisiones del número de permisos que se otorgan dependiendo de las necesidades del mercado de trabajo. Se establece un período inicial de residencia de dos años, con la posibilidad de conseguir la residencia permanente a partir de un sistema complejo de extensiones y renovaciones del permiso. Se reconoce también la posibilidad de reunificación familiar a aquellos/as que cumplen los términos legales y disponen de una vivienda adecuada. La Ley Martinelli establece los motivos por los que los/as extranjeros pueden ser deportados: desorden público, ofensas criminales importantes, incumplir las reglas de residencia, no pagar impuestos, destruir patrimonio nacional artístico, o por ofensas sexuales.

Las medida más relevante que prevé la Ley 943 es una regularización a gran escala de inmigrantes indocumentados/as. El período de amnistía empieza en enero de 1987 y en principio debe durar tres meses, aunque se extiende con prórrogas sucesivas hasta septiembre de 1988. La Ley Martinelli introduce un segundo período de amnistía que empieza en diciembre de 1989 y acaba en junio de 1990 . Se espera que esas regularizaciones no sólo benefician al Estado introduciendo un grado más alto de control sobre el fenómeno de la inmigración sino también a los/as propios inmigrantes al proveerles derechos asociados al status de residencia legal. Ninguno de los dos procesos de regularización es demasiado exitoso. En el primero se regularizan 120.000 inmigrantes, y en el segundo 240.000 (Sopemi, 
1992). La razón más importante para justificar esa tasa tan baja de regularización es que muchos inmigrantes ven más desventajas que ventajas en registrarse. Existe miedo a que la regularización represente la pérdida del trabajo que se realiza ya que la mayoría de inmigrantes clandestinos trabajan en la economía sumergida ${ }^{19}$. Otra razón es que un número elevado de inmigrantes no pretenden permanecer mucho tiempo en Italia. Según una encuesta llevada a cabo por CENSIS en 1990 sólo un $30 \%$ de los/as inmigrantes entrevistados desean permanecer en Italia.

En España, el status de los/as inmigrantes no comunitarios se regulariza a partir de las provisiones contenidas en la Ley Orgánica de derechos y libertades de extranjeros residentes en España de julio de 1985. La ley determina tres tipos de permiso de residencia: un permiso inicial que puede tener una durabilidad de tres meses a dos años, un permiso ordinario válido por cinco años y un permiso especial válido por diez o más. Se necesita también permiso de trabajo, aunque ese trabajo sea por menos de tres meses. La renovación del permiso laboral depende de la situación del/la inmigrante en el mercado de trabajo y la existencia de acuerdos bilaterales con el país de origen. La deportación se puede ordenar judicialmente como resulta de una ofensa criminal o administrativamente si las condiciones de residencial legal no son cumplidas. La posibilidad más relevante que contempla la ley es la de regularizar personas extranjeras que no tienen la documentación en regla. Se abre un período de amnistía con un resultado final pobre; se reciben solamente 38.000 demandas de las que se aprueban un 94\%.

En junio de 1990 Izquierda Unida eleva una propuesta a las Cortes urgiendo al gobierno a presentar un informe sobre la situación de los/las extranjeros en España. La propuesta demanda la regularización del status de extranjeros que residen y trabajan en España durante un período de tiempo largo, el derecho de las familias a reunirse, y que se inicie el borrador de una ley de inmigración nueva. En marzo de 1991 se presenta una resolución en la que todos los grupos parlamentarios excepto Izquierda Unida están de acuerdo. Se pretende organizar y controlar la inmigración extracomunitaria dependiendo de la forma en que la sociedad española asimile las entradas de personas extranjeras. Se decide reforzar las medidas internas y externas de control. Las medidas externas incluyen la modernización de las aduanas y la extensión del número de países a los que se exigen visados de entrada. Las medidas internas incluyen un programa de integración social para inmigrantes en los sectores de empleo, salud, vivienda y protección social. Se debe completar el programa de regularización llevado a cabo en 1985 y regularizar los trabajadores extranjeros que hayan llegado desde ese momento y estén trabajando en condiciones de irregularidad. También se imponen multas de cuantía mayor a las personas que empleen inmigrantes ilegales. Se intenta reducir el número de personas que piden asilo o refugio para desincentivar el mal uso del sistema de protección de refugiados que a juicio del gobierno lo que realmente hace es promover la inmigración ilegal. Se desea también promover la ayuda para el desarrollo económico de las áreas de las que provienen la mayoría de inmigrantes ilegales, principalmente las norteafricanas.

La resolución se pone en práctica en España de forma parcial. En 1991 y en 1993 se ponen en marcha dos programas más de amnistía en los que se legaliza el status de más de 100.000 personas cada vez. En la Tabla 9 se presentan datos del programa de regularización de status laboral de 1991 donde se regularizan algo más de 125.000 personas. Un $44 \%$ de los inmigrantes irregulares que desean legalizar su situación son marroquíes. Es el contingente más alto y de ello se deduce que la mayoría de inmigrantes ilegales residentes en España provienen de ese país. Cerca de un 20\% de regularizaciones las solicitan inmigrantes procedentes de países latinoamericanos, y algo más de un $5 \%$ inmigrantes son chinos/as. Se aprueban el $90 \%$ de las peticiones. En el caso de inmigrantes marroquies se deniegan un 14\%, y en el caso de los/as inmigrantes chinos más del $40 \%$. A partir de abril de 1991 se exige visado a las personas que provienen de los países del Magreb aunque la visita que realizan sea de corta duración o por turismo. Se firma un tratado de colaboración entre los gobiernos español y marroquí para controlar la inmigración clandestina, y se asigna más personal de la administración española para vigilar la frontera con Marruecos. En opinión de Colunson (1996: 58), el hecho que refleja de manera más clara el cierre de las fronteras de la Unión Europea a la entrada de inmigrantes procedentes de los países del sur y este de la cuenca son los tratados bilaterales. En febrero de 1992 España y Marruecos firman un acuerdo de readmisión en Marruecos de inmigrantes indocumentados de origen marroquí o que penetren en España viajando a través de Marruecos. Marruecos se compromete a controlar los/as inmigrantes ilegales procedentes de países del África subsahariana que intentan entrar en España a través de Marruecos. A cambio, España facilita el acceso por sus fronteras de inmigrantes marroquíes legales procedentes de países de la Unión Europea que visitan a sus familias en Marruecos. Colunson (1996: 59) denuncia el trato que reciben los/as inmigrantes deportados a Marruecos. «Un número importante de marroquíes deportados a Marruecos por las autoridades españolas son juzgados en Tánger; mientras que cientos de personas procedentes de Senegal, Malí y otros países al sur de Marruecos deportadas por el gobierno español o apresadas por el marroquí antes de entrar en España son encarceladas en Marruecos durante periodos de tiempo indefinidosn. En junio de 1991 se firma el Acuerdo de Schengen, que entra en vigor en marzo de 1995. De momento, los gobiernos españoles parecen haberse olvidado de la parte de la resolución que habla de la intención de crear un programa para facilitar la integración de los trabajadores inmigrantes a la Comunidad. 


\section{Tabla 9}

Demandas de regularización de status laboral en España en 1991

\begin{tabular}{|c|c|c|c|c|}
\hline \multirow{2}{*}{ Procedencia } & \multicolumn{2}{|c|}{ Total } & \multicolumn{2}{|c|}{ Denegadas } \\
\hline & Número & $\begin{array}{l}\text { Porcentaje } \\
\text { del total }\end{array}$ & Número & $\begin{array}{c}\text { Porcentaje } \\
\text { de denegadas }\end{array}$ \\
\hline \multicolumn{5}{|l|}{ Del Mediterráneo Norte } \\
\hline Portugal & 1.212 & $0,9 \%$ & 28 & $2,3 \%$ \\
\hline \multicolumn{5}{|l|}{ Del Mediterráneo Sur } \\
\hline Marnuecos & 56.276 & $44,0 \%$ & 7.992 & $14,2 \%$ \\
\hline \multicolumn{5}{|l|}{ De otros paises europeos } \\
\hline Polonia & 3.454 & $2,7 \%$ & 142 & $4,1 \%$ \\
\hline \multicolumn{5}{|l|}{ De otros países del mundo } \\
\hline Estados Unidos & 1.076 & $0,8 \%$ & 45 & $4,2 \%$ \\
\hline Argentina & 7.729 & $6,0 \%$ & 314 & $4,1 \%$ \\
\hline Uruguay & 1.576 & $1,2 \%$ & 84 & $5,3 \%$ \\
\hline Chile & 2.447 & $1,9 \%$ & 116 & $4,7 \%$ \\
\hline Brasil & 1.645 & $1,3 \%$ & 142 & $8,6 \%$ \\
\hline Penú & 5.908 & $4,6 \%$ & 231 & $3,9 \%$ \\
\hline Colombia & 2.323 & $1,8 \%$ & 188 & $8,1 \%$ \\
\hline Filipinas & 2.693 & $2,1 \%$ & 81 & $3,0 \%$ \\
\hline República Dominicana & 5.780 & $4,5 \%$ & 233 & $4,0 \%$ \\
\hline China & 6.926 & $5,4 \%$ & 2.865 & $41,4 \%$ \\
\hline Otros paises & 15.050 & $11,8 \%$ & 1.768 & $11,7 \%$ \\
\hline Total & 127.825 & $100 \%$ & 19.453 & $15,2 \%$ \\
\hline
\end{tabular}

Fuentes: Sopemi, Trends in International Migration: Continuous Reporting System of Migration (París: OECD, 1992), p. 92.

Nota: Se citan los 13 países con un porcentaje mayor de demandas para regularizar el statu laboral. En cada bloque, los paises están ordenados según su renta per capita en el año 1992.

Existen implicaciones importantes en el control de la inmigración indocumentada derivadas de las características del mercado laboral en los países del sur de Europa. Se observan conexiones fuertes entre la economía sumergida y el empleo de inmigrantes indocumentados. Debido a la importancia de la economía sumergida en esos países es posible cuestionar su capacidad, e incluso su adeseo" de forzar controles internos estrictos o sanciones a empresarios que den trabajo a inmigrantes ilegales. TAPINOS (1991) considera que los países ricos del norte de Europa presionan a los países del sur para que enderezcan las medidas restrictivas de entrada de inmigrantes. Al mismo tiempo, los autoridades políticas en el sur de Europa son pre- sionadas por círculos empresariales poderosos que tienen intereses para que continúen los flujos de mano de obra barata desde el norte de África. Según Brochman (1993), existe un cisma interno aparente dentro de la Unión Europea a nivel político. Los países meridionales podrían utilizar su ventaja comparativa en la obtención de mano de obra barata del norte de África para neutralizar la posición favorable que tiene Alemania respecto de los/as inmigrantes del este de Europa.

Desde principios de la década de los ochenta la situación del fenómeno migratorio en el Mediterráneo es compleja. La posibilidad de una migración masiva de personas del norte de África al sur de Europa debida a los diferenciales demográficos y económicos que presentan los países de las dos orillas del Mediterráneo es una preocupación importante para los Estados miembros de la Unión Europea. Sin embargo, a pesar de los temores reflejados por esos países miembros de la UE, el análisis de los datos estadísticos demuestra que el boom inmigratorio de personas procedentes de los países del norte de África hacia los países del sur de Europa no se produce (véase la Tabla 10). Es cierto que sacar conclusiones de datos estadísticos sobre inmigración en el sur de Europa es difícil debido a los numerosos canales de inmigración, a las categorías diversas de inmigrantes, y a que las definiciones y sistemas de recolección de datos difieren de un país a otro. A pesar de la dificultad de análisis de los datos, es posible constatar que el volumen de inmigrantes residentes en los países de Europa meridional sigue siendo bastante menor que el volumen residente en Europa septentrional.

En los países del sur de Europa la inmigración ilegal es un componente del total de población extranjera residentẻ más alto que en Europa central o del norte. Debido a la variedad de las situaciones de irregularidad entre la población inmigrante, la dimensión cuantitativa de la inmigración irregular desde países del norte de África a países del sur de Europa sólo puede ser estimada de forma precaria. Pero aunque el análisis de la migración en los países meridionales incluya estimaciones de aquellas personas que entran en el país evitando los controles de frontera, o de personas que están en situaciones de irregularidad derivadas de formas legales de migración, el volumen de inmigrantes en los países meridionales de Europa sigue siendo bastante menor que en el Centro y Norte. Los tres millones de personas extranjeras residentes en Italia, España, Portugal y Grecia -contando además de los/as inmigrantes legales las estimaciones más elevadas del número de inmigrantes ilegales que son las del Consejo de Europa - representan el 2,5\% del total de la población de los cuatro países. Es una cifra bastante menor que 4,3\%, que es la tasa media de inmigrantes legales residentes en los países de la Unión Europea según Eurostat, y menos de la mitad si se tienen en cuenta también las estimaciones de ilegales. Los flujos de inmigrantes siguen siendo más importantes en volumen en los países septentrionales de Europa 


\begin{tabular}{|c|c|c|}
\hline \multicolumn{3}{|c|}{$\begin{array}{l}\text { Tabla } 10 \\
\text { es) magrebies en el sur de } \\
\text { opa de } 1991\end{array}$} \\
\hline \multirow{2}{*}{$\begin{array}{l}\text { Paises de la } \\
\text { Europa meridional }\end{array}$} & \multicolumn{2}{|r|}{ Magrebies (a) } \\
\hline & Miles & $\begin{array}{l}\% \text { respecto del total de } \\
\text { extranjeros/as regularizados }\end{array}$ \\
\hline Italia & 132,2 & $15,8 \%$ \\
\hline España & 29,5 & 6,1 \\
\hline Portugal & 0,1 & 0,1 \\
\hline Grecia & 0,9 & 0,4 \\
\hline Totaluy $\therefore$ & 153,7 & 9,8 \\
\hline Totall $\mathrm{CE} \quad, \quad, \quad$. & & $13,3 \%$ \\
\hline
\end{tabular}

Fuente: Eurostat. Rapid Reports: Population and Social Conditions: 1993 (Luxemburgo: Comunidad Europea, 1993), pp. 6-7.

Nota: Se analiza Portugal, España, Italia y Grecia porque son paises que invierten sus patrones de migración. Pasan de ser paises de emigración a paises de inmigración.

(a) Magrebies se refiere aquí a la población nacida en Marnecos, Argelia o Túnez.

que en los meridionales. Sobre todo, es debido a procesos de reunificación familiar y al número elevado de peticiones de asilo. El volumen de los flujos de inmigración dirigidos a los países del sur de Europa incrementa rápido, pero aún no se equipara a los del norte.

España, Italia, Grecia y Portugal son cada vez emplazamientos más atractivos para los/as inmigrantes que cruzan el Mar Mediterráneo debido a su desarrollo económico reciente. Pero los países centro y norteuropeos siguen siendo aún más atractivos. Para un componente importante de los/as inmigrantes que residen en los países del sur de Europa, ésos son una puerta de acceso a otros países de la UE (BLANCO, 1993: 171). En 1990 CENSIS realiza un estudio en Italia en el que se demuestra que el $70 \%$ de inmigrantes norteafricanos/as reside provisionalmente en Italia y desea emigrar cuando pueda a países más al norte. Los datos estadísticos sobre el volumen de inmigración en los países del sur de Europa teniendo en cuenta las estimaciones más elevadas de inmigración irregular son suficientes para confirmar que la supuesta inmigración masiva a Europa procedente de los países del sur de la cuenca mediterránea aún no se ha producido. Es preciso explicar por qué existe el temor entre los paises de la Unión Europea de una migración masiva de personas procedentes del otro lado del Mar Mediterráneo, qué tipo de políticas restrictivas de la migración se aplican debido a ese temor, y cuáles son las razones para que ese flujo masivo de inmigración entre el sur y el norte de la cuenca mediterránea no se produzca de momento.
Ese temor por parte de los países de la Unión Europea a una inmigración masiva proveniente de los países del sur de la cuenca mediterránea es debido en parte a que predicen movimientos de población en base a teorías antiguas y la mayoría de veces demasiado restrictivas. Las variables culturales y sociológicas normalmente no son tenidas en cuenta. En Europa una mayoría de los/as investigadores interesados en el tema de la migración y los desplazamientos humanos continúan utilizando pautas teóricas derivadas de los patrones "clásicos" iniciados por RAVENSTEIN hacia 1880. MASSEY y otros argumentan que ael boom reciente en inmigración toma a los científicos sociales por sorpresa y gran parte de los estudios utilizan aún conceptos, modelos y asunciones del siglo pasado" (1993: 432). Las teorías clásicas conceptualizan la migración como realocación de seres humanos en el espacio dentro de un mismo país o entre países. Pretenden encontrar modelos formales que sean capaces de explicar esos movimientos. RAvENSTEIN afirma que "la principal, aunque no la única, causa de las migraciones hay que buscarla en la sobrepoblación de una parte del país, mientras en otras partes existen recursos infrautilizados que contienen una promesa mayor de trabajo remunerado" (1985: 198). En la primera de sus Leyes de las migraciones que son deducidas a partir del análisis de veinte países afirma que, aaunque existen corrientes [migratorias] debidas a otros motivos, ninguna puede compararse en volumen con la que resulta del deseo inherente a la mayoría de los hombres de progresar en cuestiones materiales (RAVENSTEIN, 1889: 286). La materia prima que Ravenstein estudia, y a la que se refieren sus leyes son migraciones internas. Pero, en opinión de ARANGo (1990: 117), ala mayor parte, si no la totalidad de lo que dice, es [...] aplicable a las migraciones internacionales; con la particularidad de que las disparidades que encuentra en la raíz de las migraciones -entre sobrepoblación relativa y abundancia de oportunidades económicas - son mayores [...] entre países que [...] entre regiones de un mismo país. Y ello es cierto tanto en términos económicos, o de niveles de desarrollo -el famoso contraste Norte/Sur-, como en lo que atañe [al factor] demográfico, entre otras cosas porque ambos órdenes de desigualdad aparecen estrechamente asociados ${ }^{20}$. Davis (1988: 259) atribuye la tendencia a ofrecer explicaciones económicas de los/as científicos sociales que estudian el proceso migratorio a su falta de habilidad para tener en cuenta la multiplicidad de factores incluidos en el proceso de migración internacional. Los factores microeconómicos basados en la elección racional de las personas no acostumbran a analizarse al mismo tiempo que factores estructurales (macro) como presiones demográficas, económicas y sociales.

La explicación más popular de la migración internacional es la ofrecida por los macroeconomistas neoclásicos. Ese punto de vista influencia el pensamiento público y provee las bases intelectuales que justifican gran parte de las políticas de inmigración. Según la economía neoclásica en su vertiente macroeconómica, la 
migración internacional es causada por diferencias geográficas entre la oferta y la demanda de trabajo. Países con una proporción elevada de trabajo relativa al capital tienen un salario de equilibrio de mercado bajo mientras que países con una proporción limitada de trabajo se caracterizan por un salario de mercado alto. Se demuestra a partir de la interacción entre las conocidas curvas de oferta y demanda. El diferencial en los sueldos provoca que los/as trabajadores que provienen del país con salarios bajos emigren al país con salarios altos. Como resultado de ese movimiento la oferta de trabajo desciende y los sueldos aumentan en el país con carencia de capital, mientras que la oferta de trabajo incrementa y los salarios caen en el país con capital abundante. La tendencia al equilibrio se refleja en un flujo de trabajadores/as que se desplazan de los países con mano de obra abundante a los países con mano de obra escasa; y un flujo de capital en sentido contrario. La escasez relativa de capital en los países más pobres implica una tasa de retorno alta, atrayendo por lo tanto inversión. El movimiento de capital incluye también capital humano; trabajadores cualificados que viajan de los países ricos a los pobres para obtener salarios altos por sus habilidades en un medio ambiente con capital humano cualificado escaso.

Esa perspectiva contiene algunas proposiciones y asunciones implícitas. En primer lugar, la migración internacional de trabajadores es producto de diferencias en los salarios de los países. La eliminación de los diferenciales de salario detiene el movimiento de trabajadores; la migración no ocurre en la ausencia de esos diferenciales. En segundo lugar, flujos internacionales de capital humano (trabajadores cualificados) responden a las diferencias en la tasa de retomo de capital humano que pueden ser distintas del ratio de salarios global conduciendo a un patrón distinto de migración opuesto al de los/as trabajadores no cualificados. En tercer lugar, los mercados de trabajo son los mecanismos por los cuales son inducidos los flujos internacionales de trabajo; otros tipos de mercado no tienen efectos importantes en la migración internacional.

Las políticas de migración en los países europeos se ven influenciadas por la definición del fenómeno migratorio que ofrece la economía neoclásica. Las políticas de migración internacional dependen de ese punto de vista teórico y de la posición oficial (positiva o negativa) que los países toman en torno al fenómeno migratorio. Se refleja en unos tipos explícitos de políticas y regulaciones que los Gobiernos adoptan para controlar la salida y la entrada tanto de extranjeros/as como de ciudadanos/as. A veces una aplicación laxa, o una interpretación flexible de esas políticas y regulaciones existentes, conduce a resultados que difieren de forma considerable de los que se pretenden al principio. Coluinson (1994) considera que debido a la velocidad que los países del sur de Europa tienen que desarrollar las políticas restrictivas de inmigración, y debido a la carencia de tradición previa en regular la inmigración, la habilidad de los Gobiernos de esos países para controlar los flujos de inmigrantes a un nivel similar a los países del norte de Europa debe ser puesta en duda.

Las políticas de inmigración se suelen enfocar de dos maneras: utilizando controles de frontera, o apoyando el desarrollo económico en los países fuente de inmigración. Los países europeos ponen énfasis en el primer sistema. Existe un consenso entre los Estados europeos de que la inmigración irregular debe ser restringida tanto como sea posible utilizando medidas de control directo. Las más frecuentes son los controles externos para evitar la entrada inicial de los/as inmigrantes ilegales en el país. Esas medidas incluyen políticas de restricción de visados, controles en los puntos principales de entrada, así como patrullas de frontera y costa. El consenso europeo sobre la necesidad de tomar medidas de control estrictas se obtiene a partir de acuerdos intergubernamentales entre todos los países miembros de la Unión Europea (UE). Esos acuerdos están reglados por la ley internacional y no precisan de instituciones de la UE para su funcionamiento. El más importante es el Acuerdo de Schengen que se pone en marcha en marzo de 1995 por los Estados miembros, excepto por Italia y Grecia que en ese momento aún no cumplen los requisitos. El Acuerdo de Schengen implica a la vez la construcción de una frontera común exterior, y el libre movimiento de los ciudadanos/as dentro de la UE. Representa además un intento de coordinar las diferentes fuerzas policiales europeas, así como la puesta en marcha del Sistema de Inteligencia de Schengen (SIS), que es un sistema computarizado de ficheros referentes a población deportada, criminales peligrosos, traficantes de drogas o armas, y personas desaparecidas. Los países europeos aplican ese tipo de política migratoria restrictiva de forma dual. Por un lado, se restringe la inmigración introduciendo controles de entrada. Por otro lado, se promueve la integración de la población extranjera que ya reside dentro de las fronteras de esos países. En palabras de Sarah Coluinson (1994: 160), se está creando The Fortress Europe (la fortaleza Europa).

La segunda manera de enfocar las políticas de migración es apoyando el desarrollo económico y las oportunidades de empleo en los países que son fuente de esa inmigración. Tal como afirma MASSEY, «el desarrollo económico es la aplicación de capital para aumentar la productividad humana, generar riqueza e incrementar la renta nacional. Asociado a él encontramos una constelación de cámbios sociales y culturales que los científicos sociales llaman generalmente 'modernización'. El desarrollo económico y la modernización son dependientes mutuamente y se refuerzan. El desarrollo económico no depende solamente de las cantidades de trabajo y capital sino también de factores institucionales culturales y tecnológicos que determinan la cantidad de trabajo y capital que debe ser utilizado. Al mismo tiem- 
po, la acumulación de capital transforma las instituciones sociales, los valores culturales y las tecnologías de manera que afectan la evolución del desarrollo subsiguiente (1988: 383). Una creencia común entre las personas que diseñan estrategias antiinmigratorias es que la emigración de los países en vías de desarrollo se debe a la carencia de desarrollo económico a nivel local o nacional. Tal como explica la teoría macroeconómica neoclásica de migración, las. personas dejan sus lugares de origen porque sus países son pobres, subdesarrollados y por lo tanto no ofrecen oportunidades económicas suficientes. Se emigra a paises desarrollados y ricos para encontrar un número mayor de oportunidades de empleo, así como salarios más altos. Desde esa perspectiva, la manera más eficiente que tienen los países desarrollados para controlar la inmigración es promover el clesarrollo económico de los países fuente de emigración. Cuando los estándares de vida se igualan, los incentivos económicos que conducen a movimientos internacionales de población desaparecen y la emigración a gran escala se reduce.

Una política de inmigración restrictiva parece ser una solución inadecuada para controlar los flujos de migración en el Mediterráneo puesto que el número de inmigrantes ilegales deriva precisamente de las desigualdades demográficas y socioeconómicas. BEHROUN -entre otros- argumenta que esas mediclas pueden ser efectivas durante un período corto de tiempo (1993: 35). Para conseguir una solución positiva definitiva, lo mejor que los países de la Unión Europea pueden hacer es optar por una política de cooperación con los países del norte de África en la que el desarrollo económico está conectado con políticas de inmigración. La aplicación de lo primero resulta en la reducción de lo segundo. En otras palabras, se trata de resolver las causas que producen emigración. La idea que yace detrás de la recomendación de BEHROUN se implementa por la UE en octubre de 1994. La Comisión publica una comunicación en la que promueve relaciones entre la UE y los países del norte de África. Se propone un programa ambicioso para construir sobre las relaciones económicas y políticas entre la UE y los países del sur de la cuenca mediterránea. El deseo a largo plazo es crear un área económica euro-mediterránea. Las medidas más importantes que se toman hasta el momento pretenden liberalizar las relaciones entre los Estados mediterráneos y la Unión Europea para crear un área libre de comercio. Se avanza en el proyecto de manera sustancial con la firma de la Iniciativa de Cooperación Euro-Mediterránea en la reunión de Barcelona en 1995. Las nuevas políticas que se aprueban incluyen un aumento de la asistencia financiera de la UE a los países del sur y este de la cuenca. A pesar de esas medidas, los gobiernos de los Estados europeos argumentan que el desarrollo económico sostenido de los países mediterráneos africanos y asiáticos sólo se puede asegurar a partir de una expansión del comercio exterior. El tratado no permite la entrada de trabajadores procedentes de países del norte de África.
Se argumenta que el comercio internacional representa una alternativa a la migración internacional. De manera ideal, una apertura al comercio internacional de las economías de los países que son fuente de migraciones debe representar mejoras económicas en esos países debido a la inversión en la producción de bienes orientados a la exportación. La reactivación del sector secundario de esos países debe conducir a un crecimiento económico más rápido y a la expansión del mercado laboral local. Anne RichARDS argumenta que debido a aaumentos substanciales del número de personas empleadas en los sectores de producción [de esos países] el diferencial entre salarios locales y foráneos debe disminuir, y la migración debería dejar de ser una opción tan atractiva" (1994: 153). La liberalización del comercio debe animar a los/as inversores que van a crear empleos a trasladar trabajadores especializados de los países con capital abundante a los países que son fuente de migración. Mantener los mercados cerrados, por el contrario, anima a los trabajadores a emigrar desde los mercados con excedente laboral a los mercados protegidos de los países ricos. Georges TAPINOS afirma que ala hipótesis del comercio internacional como sustituto de la migración se secunda por la experiencia de la Comunidad Europea; donde el Mercado Común conlleva una disminución de las diferencias en calidad de vida en los Estados miembros y la reducción de los niveles de migración intra-comunitaria" (1994: 220). La experiencia europea no parece ser aplicable al Mediterráneo donde las desigualdades económicas son mayores que las de los Estados miembros de la UE cuando se integran al Mercado Común. Además, la mayoría de los países africanos y asiáticos de la cuenca fracasan en desarrollar el sector secundario. Acostumbra a ser pequeño, ineficiente, poco flexible, y ofrecer una cantidad de productos limitada.

La paradoja es que, a corto plazo, la liberalización del mercado o las políticas de apoyo al desarrollo económico y las oportunidades de empleo en los países que son fuente de migración son ineficientes e incluso contraproducentes; si bien a largo plazo sí son efectivas. Por ejemplo, la emigración desde los países desarrollados de Europa a Estados Unidos es hoy en día una fracción de lo que fue siete u ocho décadas atrás cuando esos países estaban en vías de desarrollo. A corto plazo, el desarrollo no reduce la tendencia a emigrar, sino que la incrementa. Según MaSSEY, «en el proceso de desarrollo económico los países pasan de ser sociedades rurales agrarias con instituciones a pequeña escala, estructuras sociales estables y mercados limitados, a ser sociedades industriales urbanizadas dominadas por grandes burocracias institucionales, organizaciones sociales fluidas y mercados fuertes e integrados. Ese proceso de transformación es inherentemente revolucionario y altamente disruptivo y, por lo tanto, desplaza mucha gente de los sistemas de vida tradicionales. Esas personas desplazadas constituyen la fuente de los movimientos de población masivos que de forma inevitable acompañan al desarrollo [...] muchos se 
convierten en inmigrantes internacionales que buscan oportunidades en economías más dinámicas en el extranjero" (1988: 383384). Ese hecho sucede históricamente en Europa Occidental y es igualmente verdad hoy en día en algunos países en vías de desarrollo. La emigración incita a cambios en las estructuras sociales y económicas del país de origen que presionan para que la emigración al extranjero sea aún más frecuente y posible. Cuando ese proceso de causalidad acumulativa tiene lugar, los esfuerzos para reducir y controlar el flujo de inmigrantes son costosos y difíciles. Un punto de vista realista de la relación entre migración y desarrollo económico sugiere que las políticas de promoción del desarrollo económico en los países que expelen emigrantes no reducen la emigración a corto plazo, sino que la aumentan.

Si la Unión Europea pretende reducir la inmigración procedente de los países del norte de África promoviendo el desarrollo de esos países, debe esperar que los flujos de inmigración continúen e incluso se incrementen a corto plazo a medida que la mejora económica elimina los incentivos para el movimiento a largo plazo. Maximizar a corto plazo de manera simultánea los objetivos de un desarrollo económico rápido en los países del sur del Mediterráneo, y el decremento de la inmigración en dirección a Europa Occidental es una tarea difícil. Si la Unión Europea está interesada en promover el desarrollo económico acelerado en los países del sur del Mediterráneo, debe también estar interesada en aceptar números grandes de inmigrantes procedentes de esos países. En opinión de CAGIANO DE AZEvEDo, ala idea de promover el desarrollo general en los países del norte de África es loable, pero promoverla con la condición de que exista una ausencia total de flujos de migración es irreal e insuficiente "(1993: 19). Parece evidente que contribuir al desarrollo de un país no implica solamente invertir fondos o favorecer las inversiones productivas locales, sino también aceptar -al menos temporalmente- la inmigración de ciudadanos/as.

La aceptación por parte de los países de la Unión Europea de flujos migratorios procedentes de los países del sur de la cuenca mediterránea es difícil. Existen constricciones culturales, ideológicas y políticas que son difíciles de superar. El Mar Mediterráneo es un área clave para mantener la seguridad global que es un concepto surgido de la corriente de la investigación para la paz. Conforma un área militar estratégica debido a que está situado en la encrucijada de tres continentes y reviste un interés posicional evidente en la lucha por la hegemonía mundial. Es zona de paso y por ella transita un tercio del tráfico mundial de petróleo. Después de la Segunda Guerra Mundial, Estados Unidos y la Unión Soviética intervienen en él directamente con sus escuadras, o indirectamente con ayuda económica a algunos países, abastecimiento de armas, o alianzas destinadas a la protección de sus intereses.
Es un mar parcelado y compartimentado, aunque no cerrado ya que el canal de Suez lo une al Mar Rojo; también se comunica con el Atlántico por el estrecho de Gibraltar y con el Mar Negro por el estrecho de los Dardanelos y el Bósforo. Es un mar fácil de controlar, las puertas del Mediterráneo son también sus cerrojos.

Globalizar el discurso sobre la seguridad en el Mediterráneo trae como consecuencia presentar algunas cuestiones socio-económicas o políticas como amenazas a tener en cuenta. Se presentan los elementos de desestabilización interna de los países africanos y asiáticos de la cuenca mediterránea como una amenaza para Occidente. Esa amenaza no militar afecta a los países europeos industrializados que asocian los problemas y las soluciones derivadas de la misma más a ellos que a la población de los países del sur y este de la cuenca. El desarrollo económico o social de los países mediterráneos africanos y asiáticos, así como los procesos políticos de democratización se entiende que son instrumentos de prevención de conflictos para los intereses occidentales y no soluciones a problemas internos de esos países. La prioridad principal de los países europeos es evitar una migración masiva procedente de los países del otro lado de la cuenca mediterránea. El primer escalón en materia de seguridad es evitar que a partir de la inmigración se importen problemas sociales de esos países. La inseguridad cotidiana en las poblaciones del Sur es una amenaza futura para las del Norte. En la UE, y sobre todo en la Europa latina, la política de seguridad con respecto a los países del sur y este de la cuenca está determinada por el problema del control y la gestión de los flujos inmigratorios.

El reto para Europa consiste en evitar que el diferenciar demográfico, sustentado en la crisis estructural de los países del sur de la cuenca se traduzca en una oleada migratoria hacia el Norte. Existen diferencias demográficas entre las dos orillas de la cuenca que se desarrollan sobre un fondo de crisis económica en los países del sur y este. ARANGO afirma que alas disparidades demográficas existentes lentre las dos orillas de la cuenca mediterráneal son las más conducentes, ceteris paribus, a fuertes migraciones [...] Son máximas en fecundidad y mucho menores en materia de mortalidad y esperanza de vida. Como consecuencia de la combinación de ambas, son extremas en lo que se refiere al ritmo de crecimiento de la población. Por ser máximas en fecundidad, lo son también en cuanto a la estructura por edades de la población [...] Mientras unas [sociedades] son extremadamente jóvenes, las otras se encuentran embarcadas en un proceso de progresivo envejecimiento (1990: 119). El primer problema demográfico que puede ser generador de inmigración es el contraste numérico entre las dos orillas. La fecundidad es más elevada en los países de las orillas sur y este del Mediterráneo que en la orilla norte. En 1994, en los países de la Europa mediterránea, la media de fecundidad es de 1,5 
niños/as a lo largo de la vida reproductiva de la mujer. En los países africanos y asiáticos del Mediterráneo, la mujer casada tiene de promedio cuatro hijos/as. En los países europeos del Mediterráneo hay 11 nacimientos por cada mil habitantes; mientras que en los países africanos y asiáticos esa media es casi tres veces superior. Esas diferencias se reflejan directamente en las tasas de crecimiento vegetativo, que en el Sur son casi diez veces mayores que en el Norte. No existe una diferencia clara en las tasas de defunción. La tasa de defunciones por mil habitantes es de siete en los países del área sur y este del Mediterráneo, y de nueve en los países de la orilla norte donde la estructura de edades es más envejecida.

El contraste entre la estructura por edades propia de cada una de las orillas de la cuenca mediterránea es también una causa posible de migraciones. El porcentaje de personas muy ancianas (75 años y más) que viven en los países del sur y este de la cuenca es pequeño, tan sólo el 1,4\% del total de la población. La proporción de ancianos/as de 65 a 74 años también es reducida (3\%); representa tan sólo una tercera parte de los/as ancianos que residen en los países europeos del Mediterráneo. El porcentaje de niños/as de la población es más alto en los países del sur y este de la cuenca mediterránea que los del norte. El porcentaje de población infantil (hasta cuatro años de edad) en los países africanos y asiáticos del Mediterráneo es casi tres veces mayor que en los europeos: $14 \%$ por $6 \%$ respectivamente. La proporción de niños/as de cinco a 14 años es dos veces mayor en los países del sur que en los del norte $(26 \%$ y $13 \%$, respectivamente). Los diferenciales demográficos suceden a la vez que diferenciales económicos paralelos. La década de los ochenta y los primeros años noventa representan un periodo negativo desde el punto de vista de crecimiento económico para la mayoría de países africanos y asiáticos de la cuenca del Mediterráneo. A lo largo de ese período histórico las diferencias económicas Norte/Sur aumentan. En la década de los noventa los países del norte de la cuenca son de promedio ocho veces más ricos que los del sur y este. En 1980 el PIB total de los países de la orilla norte es casi seis veces el de los países del sur y el este. En tres lustros el producto interior bruto incrementa un $150 \%$ en los países europeos y tan sólo un $80 \%$ en los africanos y asiáticos. Si en vez del PIB global se compara la media del PIB per capita entre los dos bloques de países, las desigualdades que existen entre las áreas de estudio aún aumentan más a lo largo de los tres lustros. Eso es debido a la existencia de una tasa de natalidad más elevada en los países africanos y asiáticos que en los europeos. La media del PIB per capita en los países del norte de la cuenca pasa de ser cinco veces mayor que la de los países del sur y el este en 1980, a ser ocho veces más alta $1992^{21}$. Además, los países meridionales de la cuenca sufren problemas estructurales en las últimas dos décadas. El déficit alimentario es preocupante ya que de cada dos calorías una es importada. El proceso de industrialización fracasa, la deuda ex- terna sigue siendo alta y los procesos de urbanización son rápidos y a veces caóticos. A todo ello debe añadirse a veces una crisis cultural que desemboca en una oleada de integrismo religioso.

A pesar de todos esos condicionantes, la migración masiva de personas de los países del sur y este de la cuenca hacia los del norte no se produce. El volumen de inmigrantes en los países del centro y norte de Europa se incrementa básicamente debido a la reunificación familiar y a la entrada de inmigrantes laborales y asilados/as procedentes de países del este de Europa; y los flujos de inmigrantes laborales en dirección a los países del sur de Europa son más débiles que los que veinte años antes se dirigían a los del norte. El crecimiento de población a un lado de la cuenca y el estancamiento en el otro no bastan para desencadenar movimientos de migración masivos. Son precisas otras condiciones que no se producen en la cuenca mediterránea. Es necesario que coincida una llamada de los países receptores con un rechazo fuerte en los países de origen y una situación de desgracia y desamparo. Europa, con la violencia de sus ciudades, la xenofobia que va en aumento y el crecimiento económico débil, ya no es tan atractiva como en otros tiempos. Del mismo modo, los países del sur y este de la cuenca no se encuentran en la situación precaria que conlleva migraciones por desgracia y desamparo social. En la década de los ochenta y la de los noventa se produce una mejora de algunas variables relacionadas con calidad de vida que es superior a lo que el desarrollo económico hace suponer. Debido a las políticas socialistas fundamentadas en un nacionalismo populista y desarrollista que se produce poco después de la independencia se crean Estados de Bienestar que aunque fragmentarios son eficientes en varios de sus servicios. El desarrollo de unos sectores educativo y sanitario con vocación de universalidad deriva de una ideología nacionalista que obedece a un rechazo del capitalismo extranjero, al que se culpa del subdesarrollo histórico de los países musulmanes mediterráneos. Se realizan inversiones en el sector público que son económicamente poco productivas pero tienen una repercusión social importante. Otro factor que influye en la mejora del bienestar social es que el proceso de transformación económica en los países africanos y asiáticos de la cuenca no se produce de la manera habitual, de la agricultura a la industria y de la industria a los servicios. A lo largo de los tres últimos quinquenios, los países del sur y este de la cuenca traspasan trabajadores/as del sector primario directamente al terciario, no al secundario. Debido al fracaso del proceso de industrialización, el sector secundario es poco importante en esas economías. El sector de servicios se desarrolla a la misma velocidad en los países del sur que en los del norte. Eso representa una evolución más significativa a nivel social que a nivel económico. Mejora la calidad de vida de las personas, lo que se manifiesta entre otras cosas en la mejora de la calidad de los alimentos que consumen. 
Los países europeos predicen erróneamente una avalancha de inmigrantes procedente de los países africanos de la cuenca porque entienden el concepto de proceso migratorio a partir de las premisas que ofrece la teoría macroeconómica neoclásica. Se subestiman las fuerzas que no son económicas que inducen a la migración o no de personas. El concepto de calidad de vida es crucial para entender los movimientos internacionales de personas; y ese concepto no es necesariamente económico. Las definiciones en términos de preferencias, metas o valores, sugieren que la calidad de vida es elevada alli donde se logra lo que se desea, a lo que se aspira, o aquello que es importante. El bienestar social es un concepto que puede aprehenderse a través de condiciones externas y situaciones de vida que son diferentes en cada cultura país o área de estudio. María Luisa SETIÉN define la calidad de vida como aun concepto universal, aplicable a todas las sociedades y en todos los tiempos [...] Su universalidad hace que pueda alcanzarse [...] no de una forma única, sino a través de pluralidad de acercamientos y medios diversos [...] Se concibe la calidad de vida como un concepto emparentado con el desarrollo; su medida puede considerarse una medida de desarrollo que incorpora directamente las consideraciones relativas a la mejora de la vida y al bienestar, midiendo los fines de desarrollo en términos de calidad de vida humana [...] No es considerada algo estático, sino como un proceso continuo de desarrollo. El desarrollo reviste dos facetas, es a la vez proceso y producto. La calidad de vida tiene que ver con el desarrollo como producto, pero se ve influida por el desarrollo como proceso [...] La calidad de vida, como concepto de investigación, se considera un atributo colectivo, respecto de grupos, categorías de personas, comunidades o sociedades, y no un atributo individual [...] Como tal, cualquier descripción completa de la calidad de vida puede obtenerse teniendo en cuenta el punto de vista de los individuos y de las unidades societales. El reflejo del nivel de calidad de vida se centrará preferentemente sobre los estados finales, mejor que en los medios que conducen a ella, debido a la pluralidad de medios posibles [...] La medida de la calidad de vida atenderá a las dimensiones objetiva y subjetiva de la misma" (1993: 114-115). En cualquier consideración de aspiraciones y metas interviene un elemento subjetivo de conciencia y cualquier calificación de calidad abuena" o "mala implica una percepción subjetiva de unas condiciones dadas. Ambos elementos, aspiraciones y percepciones, tienen relación con los valores e ideologías de las diferentes socieda- des, y no son siempre coincidentes con las percepciones que tienen las personas que evalúan externamente la calidad de vida.

Los/as investigadores europeos crean conceptos y variables para medir la calidad de vida desde una perspectiva etnocéntrica. "La occidentalización del mundo, es decir, la dominación del modelo cosmopolita (ya que no es necesariamente 'occidental' -expresión actualmente desterrada del vocabulario progresista- ni siquiera 'avanzada' ni 'postindustrial') sugiere que el análisis social es una parte importante del proceso de modernización y de racionalización, que a su vez supone la culminación del desarrollo humano. Se aceptan al mismo tiempo dos hipótesis etnocéntricas: la teoría de la convergencia, es decir, que las sociedades se van a parecer cada vez más; y segundo, que el modelo ideal, único, final, es el de las sociedades avanzadas (europeo-norteamericanas, además de Australia, Japón y otros países de la OCDE). A ello contribuye, claro está, la dominación estadounidense de las ciencias sociales. Con la crisis socioeconómica que se inaugura a finales de 1973 el modelo de modernización y de occidentalización se viene abajo y con él el análisis social dependiente del pomposo Welfare State (Estado de Bienestar, en horrible traducción). En la actualidad incluso los conceptos clásicos de 'desarrollo', 'organización', 'modernización' y 'racionalidad' se consideran confusos e inexactos. Se sustituyen automáticamente por los tampoco claros de 'postindustrialización', 'corporatismo', 'neomodernismo' o 'nuevas tecnologías'. En los últimos años se replantean los análisis sociales que se habían dado por buenos durante décadas" (DE MiGUEL, 1990: 37-38). No se valora el desarrollo de los países del bloque sur del Mediterráneo porque es desigual económicamente respecto de los países septentrionales. Sin embargo, el bienestar en esos países parece incrementar. No hay musulmanes/as que escriban sobre lo que para ellos/as es calidad de vida, y las opiniones de los/as científicos sociales europeos aparecen sesgadas. Es previsible un cambio en la mentalidad europea respecto al fenómeno migratorio. La migración internacional no debe ser percibida como un factor concreto de crecimiento económico (por parte de los países receptores) o de subdesarrollo (por parte de los países que expelen emigración). Puede ser también entendida como la manifestación de un grupo difuso de oportunidades y fenómenos culturales, económicos, políticos y sociales. 
- Universitat de Barcelona

1. Ejemplos relevantes de estos estudios son el libro de Michael PIORE Birds of Passage: Migrant Labour and Industrial Societies (1979), o el artículo de Alejandro PORTES - Migmation and underdevelopment (1978).

' La mayoría de flujos de migración a Europa procedentes del norte de África provienen de Marruecos, Argelia, Túnez, Egipto y Turquia. Esos cinco países representan el $86 \%$ del total de la población del sur y este del Mediterráneo.

"El primer informe oficial de desigualdades demográficas entre los países de la cuenca mediterránea, publicado en junio de 1981, concluye que: Existe una desigualdad creciente demográfica entre las riberas norte y sur-este del Mediterráneo. Al mismo tiempo, el diferencial de desarrollo está empeorando. Esos contrastes provocan inevitablemente flujos migratorios a la Europa industrializada, a los cuales puede ser negativo oponerse mientras existan contrastes económicos y demográficos agudos. Los flujos de inmigrantes tienden a distribuirse a través de Europa y empiezan a transformar lo que eran países tradicionales de emigración como España, Italia, Grecia y Portugal, en países de inmigración [...] Puede ser inocente pensar que esos países huéspedes son capaces de absorber totalmente el flujo migratorio potencial que proviene del otro lado del Mediterráneo, a la vez que la tasa inadecuada de fecundidad en los países industrializados es simplemente compensada por la inmigración. (MOTA TORRES Y VAZQUEZ, 1991: 16-17).

' Italia cambia la tendencia en 1971, España y Grecia en 1974, y Portugal en 1977.

- El mito moderno de la identidad, al mismo tiempo que crea cohesión, funciona también como mecanismo de exclusión. Ese mito es el que subyace al dogma político por antonomasia, la modema noción de ciudadanía, y a su vínculo con la nacionalidad, tal y como la heredamos de la Revolución Francesa, que está en el origen de nuestras concepciones del Estado, del Derecho, de la ciudadanía, es decir, en el núcleo del vínculo social mismo. Precisamente ese vínculo queda puesto hoy en cuestión al fracturarse algunos de los supuestos sobre los que se edificaba su pretendido universalismo, esto es, la uniformidad que el proyecto del formalismo jurídico y del libera. lismo político y económico habían tratado de poner en pie (DE LUCAS, 1996: 21).

" En todas las medidas de política (migratorial existe un punto de vista de negativo y de rechazo hacia el fenómeno migratorio que cambia poco en las dos décadas pasadas. Los países leuropeosl receptores de flujos de migración continúan viéndose como países de no-inmigración a pesar de que algunos reciben un número substancial de inmigrantes extranjeros. (Counson, 1994).

Ninguno de los procesos de regularización es demasiado exitoso. En Italia se regulariza la situación de 360.000 inmigrantes en dos períodos de amnistía, y en España de 300.000 en tres periodos de amnistía (Sopemi, 1992).

${ }^{8}$ Cambios políticos en los antiguos países comunistas de Europa, junto con eventos externos como los conflictos regionales en Yugoslavia, causan que el patrón de inmigmación europeo se altere debido a números elevados de peticiones de asilo a los paises de la Unión Europea (HaSkEY, 1992, 38).

"Experiencias pasadas demuestran que es imposible predecir la escala y dirección de los flujos mignatorios futuros, por lo que parece prematuro afirmar que la tendencia migratoria revierta definitivamente (Sopemi, 1993: 13).

iii Es la división del total de inmigrantes regularizados por el total de la población.
"Se siguen publicando numerosos artículos referentes a la migración latinoamericana a Estados Unidos, y hay un incremento importante de estudios que se refieren a la posibilidad de una migración masiva furura de personas procedentes de los NIC (New Industrial Countries) y de otros países del -lejano oriente- hacia Japón.

". Según Eurostat (1993), es en el campo de la migración donde las definiciones usadas por los diferentes Estados miembros de la Unión Europea difieren más.

1. La expresión inmigrantes legales. o su sinónimo inmigrantes regularizados. se refiere a extranjeros que poseen la autorización del país huésped que es requerida por ley para permanecer o trabajar en él (en el caso de que sean económicamente activos). Deben cumplir además las condiciones a las cuales su entrada, período de estancia, o trabajo están sujetas.

" Naciones Unidas, Organización Internacional del Trabajo y Consejo de Europa, entre otras.

15 En España las más conocidas son el colectivo IOE y el PASS.

"1i Véase por ejemplo, el trabajo de Antonio IzQuIERDo (1992) sobre el caso español.

"El número de inmigrantes ilegales en España varía según sea la fuente que ofrece la información. IOE es la primera que ofrece una cifra antes de 1990: 366.000 personas. Esa cifra se demuestra exagerada en años posteriores a raíz de la comparación con otros estudios. Ellos mismos moderan las estimaciones que cifran a partir de 1990 en 294.000 extranjeros/as ilegales, que es una cifra parecida a los 259.000 que ofrecen los informantes del PASS. Antonio IZQUIERDO, que utiliza cifras oficiales del Ministerio de Trabajo y Seguridad social en 1992, después de los dos primeros programas de regularización, estima el número de ilegales en 132.000 .

18 Es el caso de inmigrantes autorizados para trabajar en el sector agrario, y que efectúan un trabajo en el sector de servicios o industrial.

19 En Italia el marco de políticas de integración que pueden afectar de manera sustancial las condiciones de vida y trabajo de los/as inmigrantes se encuentra en un estadio de desarrollo primario. La Ley Martinelli concieme principalmente al control de la inmigración; y la Ley 943 es aun una pieza rudimentaria en materia de integración. La ley pretende garantizar a los/as trabajadores no comunitarios y a sus familias igualdad de trato y derecho de utilizar los servicios sociales y de salud. Así como mantener su identidad cultural, escolarización y vivienda. Esa legislación no se ve reforzada por un mecanismo de obligatoriedad. En la práctica, la ley da una responsabilidad considerable a las autoridades locales y el sector del voluntariado.

* .Los dos principios motrices que, combinados, laten en la mayoría de los movimientos migratorios [son] la primacía de los motivos económicos entre los múltiples discemibles en las decisiones de emigrar —dejando de lado el género especial, y crecientemente importante, de los desplazamientos forzosos causados por la violencia o por persecuciones de naturaleza política o étnica-; y la existencia de una desequilibrada distribución espacial de población y oportunidades económicas. Esta última se manifiesta en diferencias, que pueden ser muy acusadas, de renta, salarios y oportunidades de empleo. Y la percepción de estas diferencias acostumbra a actuar como detonador efectivo de los flujos migratorios. (ARANGO, 1990: 117).

"En la Europa del Mediterráneo, el PIB medio per capita aumenta en un $124 \%$ entre 1980 y 1992 , y en la parte africana y asiática de la cuenca tan sólo en un $40 \%$.

\section{Bibliografia}

Adamson, Kay. Algeria: A Study in Competing Ideologies (Londres: Cassell, 1997), 224 $\mathrm{pp}$.

Anderson, Malcom, ed. The Frontiers of Europe (Londres: Pinter Publishers, 1998), 224 $\mathrm{pp}$.

ANSARY, Abdou Filali. Perspectivas de las relaciones mediterráneas y el diálogo entre las culturas• pp. 273-284 en Enrique Viaña Remis y Miguel Hemando de Larramendi, eds. Cooperación cultural en el occidente mediterráneo (Bilbao: Fundación BBV Documenta, 1995), $545 \mathrm{pp}$.

ARANGo, Joaquín. .Disparidades demográficas y potencial migratorio en el Mediterrineo* pp. 117-135 en María Ángeles RoQUE, Movimientos bumanos en el Mediterraneo occidental (Barcelona: Generalitat de Catalunya, 1990).

ARCHDEACON, Thomas J. Reflections on immigration to Europe in light of U.S immigration history. International Migration Review, vol. 26, $\mathrm{n}^{2} 2$ (1992), pp. 525-547. 
ARvolD, Guy. The Maverick State: Gaddafi and the New World Order (Londres: Cassell, 1997); $192 \mathrm{pp}$

BALTA, Paul. El Islam (Barcelona: Salvat, 1996), 223 pp.

BEHROUN, M. International cooperation policy on immigration in Mediterranean countries• pp. 31-39 en Raimondo Cagiano de Azevedo, Paola Bacchetta y Paola Di Santo, eds. Intermational Migrations as a Factor of Security and Cooperation in Europe and in the Mediterranean Region (Rome: Università Degli Studi di Roma La Sapienza, 1993), $189 \mathrm{pp}$.

Bisar, Amer, et al. Investment and growth. pp. 7-21 en International Monetary Fund. Building on Progress: Reform and Growth in the Middle East and North Africa (Washington DC: International Monetary Fund, 1996), 69 pp.

Blanco Fernández de Valderrama, Cristina. The new hosts: The case of Spain. International Migration Review, vol. 27, $\mathrm{n}^{2} 1$ (1993), pp. 169-181.

BLot, Daniel. The Demographics of migration. The OECD Obsenver 163 (1990), pp. 21-25.

BODEGA, Isabel et al. .Recent migrations from Morocco to Spain. Intemational Migration Review, vol. 29, n² 3 (1995), pp. 800-819.

Borjas, George J. Economic theory and international migration. International Migration Review, vol. 23, $n^{2} .3$ (1989), pp. 457-485.

Borjas, George J. The impact of immigrants on employment opportunities of natives. pp. 191-198 en OECD. The Changing Course of International Migration (Paris: OECD, 1993), $264 \mathrm{pp}$

BorD, Monica. Family and personal networks in international migration: Recent developments and new agendas. International Migration Review, vol. 23, n². 3 (1989), pp. 638669.

Braudel, Femand. En torno al Mediterráneo (Barcelona: Paidós, 1997), 528 pp.

Breier, Horst. .Development and migration: The role of aid and cooperation. pp. 173186 en OECD. Migration and Development (Paŕs: OECD, 1994), 334 pp.

BrochmanN, G. .Migration policies of destination countries, pp. 23-42 en Council of Europe, Political and demographic aspects of migration flows to Europe (Estrasburgo, Council of Europe Press, 1993).

CAGIANO DE AZEVEDO, Raimondo -La política migratoria en Europa y su repercusión en los paises mediterráneos: Situación actual y futura, pp. 34-41 en Itinera: Anales de la Fundación Paulino Torras Domènecb 1989-1990 (Barcelona: Fundación Paulino Tomas Domènech, 1991), 323 pp. Ver también -Inmigración, ayuda al desarrollo y polítjca inmigratoria europea: Los casos de Italia, Espana y Portugal,, pp. 130-136.

CAGIANO DE AZEVEDO, Raimondo. Introduction: International migrations as a factor of security and cooperation in Europe and in the Mediterranean region. pp. 17-28 en Raimondo Cagiano de Azevedo, Paola Bacchetta, y Paola Di Santo, eds. International Migrations as a Factor of Security and Cooperation in Europe and in the Mediterranean Region (Rome: Università Degli Studi di Roma La Sapienza, 1993), 189 pp.

CASTELLS, Manuel. Immigrant workers and class struggles in advanced capitalism: The Westem European experience Politics and Society, vol. 5, n 1 (1975), pp. 33-66.

CENSIS. Atti della Conferenza Nazionale dell'Immigrazione (Roma: Editalia-Edizioni d'Italia, 1991a).

CENSIS. Immigrati e società italiana (Roma: Editalia-Edizioni d'Italia, 1991b)

CENSIS. Immigrazione e diritti di cittadinanza (Roma: Editalia-Edizioni d'Italia, 1991c).

COHEN, Saul B. EEl Mediterráneo occidental en el mundo de la posguerra fría. pp. 2556 en Enrique Viaña Remis y Miguel Hernando de Lamamendi, eds. Cooperación cul- tural en el occidente mediterráneo (Bilbao: Fundación BBV Documenta, 1995), 545 pp.

Colectivo IOE. Spain's illegal immigrants pp. 117-139 en T. Hammar et al, ed. European Immigration Policy (Londres: Pergamon Press, 1990).

Counsson, Sarah. Europe and International Migration (Londres: Royal Institute of Intemational Affairs, 1994), $210 \mathrm{pp}$.

Cownson, Sarah. Shore to Shore:The Politics of Migration in Euro-Maghreb Relations (Londres: Royal Institute of Intemational Affairs, 1996), 117 pp.

Commission of the European Communities. Immigration of Citizens from Third Countries Into the Southern Member States of the European Community: A Comparative Survey of the Situation in Greece, Italy, Spain and Portugal (Luxemburgo: Office for Official Publications of the European Communities, 1991), 135 pp.

Commission of the European Communities. The Demographic Situation of the European Union (Luxemburg: Office for Official Publications of the European Communities, 1994), $83 \mathrm{pp}$.

Commission of the European Communities. The Major Issues of European Demography (Luxemburg: Office for Official Publications of the European Communities, 1994), $126 \mathrm{pp}$

Council of Europe. Immigramt Populations and Demographic Development in the Member States of The Council of Europe, Part I and II (Estrasburgo: Council of Europe, 1984)

Council of Europe. Report of the New Countries of Immigration. Documment 6211, Parliamentary Assembly (Luxemburgo: Council of Europe, 1990).

Council of Europe. The Second Demograpby Transition: Fact or Fiction? (Estrasburgo: Council of Europe, 1991).

Council of Europe. Recent Demographic Developments in Europe and North America 1992 (Estrasburgo: Council of Europe, 1993), $382 \mathrm{pp}$.

Council of Europe. Political and Demographic aspects of Migration Flows to Europe (Estrasburgo: Council of Europe, 1993).

Council of Europe. Recent Demograpbic Developments in Europe 1995 (Estrasburgo: Council of Europe, 1993), $332 \mathrm{pp}$

CHALK, Nigel et al. .Financial structure and reforms. pp. 35-50 en International Monetary Fund. Building on Progress: Reform and Growth in the Middle East and North Africa (Washington DC: International Monetary Fund, 1996), 69 pp.

CHEKIR, Hafedh. Migration and development aid: The case of the textile sector in Tunisia. pp. 193-195 en OECD. Migration and Development (París: OECD, 1994), 334 $\mathrm{pp}$

CHOUEIR, Youssef. Islamic Fundamentalism (Londres: Pinter Publishers, 1997), 192 $\mathrm{pp}$.

DARBY, Phillip, ed. At the Edge of Intermational Relations: Postcolonialism, Gender and Dependency (Londres: Pinter Publishers, 1997), 224 pp.

Davs, Kingsley. Social science approaches to intemational migration. Population and Development Review, vol. 14, $n^{2} 4$ (1988), pp. 245-261.

EKEN, Sena, Thomas HelBung, y Adnan Mazarei. Fiscal structure and reforms• pp. 2335 en International Monetary Fund. Building on Progress: Reform and Growth in the Middle East and North Africa (Washington DC: International Monetary Fund, 1996), $69 \mathrm{pp}$.

El-ERlan, Mohamed A. y Susan FenNeLl. Reform and growth: An overview. pp. 1-6 en International Monetary Fund. Building on Progress: Reform and Growth in the Middle East and North Africa (Wáshington DC: International Monetary Fund, 1990), 69 pp. 
EL-ErInN, Mohamed A. et al. Growth and Stability in the Middle East and North Africa (Washington DC: International Monetary Fund, 1996), 23 pp.

EL-ERIAN, Mouhoud. Enterprise relocation, north-south economic relations and the dynamics of employment pp. 165-174 en OECD. The Changing Course of International Migration (París: OECD, 1993), 264 pp.

EMmERJ, Louis. The international situation, economic development and employment. pp. 123-130 en OECD. The Changing Course of International Migration (Pańs: OECD, 1993), $264 \mathrm{pp}$.

Esteva, Jordi. Mil i una voces (Madrid: Aguilar, 1998), $313 \mathrm{pp}$.

Eurostat. Rapid Reports: Population and Social Conditions, 1993 (Bruselas: European Comununity, 1993).

Eurostat. Migration Statistics, 1994 (Bruselas: European Community, 1994), 109 pp.

Eurostat. Demographic Statisstics, 1996 (Bruselas: European Community, 1996a), 249 pp.

Eurostat. Statistics in Foctus, 1996 (Bruselas: European Community, 1996b), 4 pp.

FaDLoUluah, Abdellatif. Migratory flows from the countries of the south to Western Europe. pp. 17.52 en Council of Europe, Political and Demiographic Aspects of Migration Flows to Europe (Estrasburgo: Council of Europe Press, 1993)

FAwCETT, James T. .Networks, linkages, and migration systems" Intermational Migration Review, vol. 23, n². 3 (1989), pp. 671-680.

Forbes MARTIN, Susan. .Development and politically generated migration. pp. 216-239 en Sergio Diaz-Briquets, y Sidney Weintraub. Determinants of Emigration from Mexico, Central America, and de Caribbean (San Francisco: Westview Press, 1991), 356 $\mathrm{pp}$.

GARSON, Jean-Pierre. Migration and interdependence: The migration system between France and Africa. pp. 80-93 en Kritz, Mary M, Lin Lean Lim, y Hania Zlotnik, eds. Intemational Migration Systems: A Global Approach (Nueva York: Oxford University Press, 1992), $338 \mathrm{pp}$.

Garson, Jean-Pierre. -Intemational migration: Facts, figures, and policy. The OECD Obsenver 176 (1992) 18-24.

GARSON, Jean-Pierre. The implications for the Mahgreb countries of financial transfers from emigrants. pp. 275-287 en OECD. Migration and Development (París: OECD, 1994), $334 \mathrm{pp}$

GILLESIE, Richard, ed. The Euro-Mediterranean Politics Partnership: Political and Economic Perspectives (Londres: Frank Cass Publishers, 1997), 193 pp.

Goss, Jon y Bruce LINDQUIST. C.Conceptualizing international labor migration: A structurition perspective. Internatinal Migration Review, vol. 29, $\mathrm{n}^{2} 2$ (1995), pp. 317-351.

Granaglia, Elena. Ethical and economic dilemmas for insertion policies for non-EC immigrants in a country experiencing immigration: The Italian caser pp. 233-238 en OECD. The Changing Course of International Migration (Paris: OECD, 1993), 264 pp.

GREGORY, Peter. The determinants of intemational migration and policy options for influencing the size of populations flows pp. $49-73$ en Sergio Diaz-Briquets, y Sidney Weintraub. Determinants of Emigration from Mexico, Central America, and de Caribbean (San Francisco: Westview Press, 1991), 356 pp.

HAMDANE, Rabah. Health industries in the Maghreb and reducing the incentive to emigrate pp. 196-200 en OECD. Migration and Development (París: OECD, 1994), $334 \mathrm{pp}$.

HammaR, Tomas. Comparing European and North American intemational migration. International Migration Review, vol. 23, $n^{2} 3$ (1989), pp. 631-637.
HASKEY, John. The immigrant populations of the different countries of Europe: Their size and origins. Population Trends 69 (1992), pp. 37-47.

International Labor Organization, World Labour Report 5: Human Rights at Work: Employment, Labour Relations, Social Protection and Working Conditions. Statistical Appendix (Ginebra: ILO, 1992).

International Monetary Fund. The role of foreign direct investment in developmentpp. 213-219 en Toivo Miljan, ed. The Political Economy of Nort-South Relations (Petersbourgh: Broadview Press: 1987), 704 pp

International Monetary Fund. Building on Progress: Reform and Growth in the Middle East and North Africa (Washington DC: International Monetary Fund, 1990), 69 pp.

Isoplan: Institute for Development Research. Economic and Social Planing (Saarbrücken/Bonn: Isoplan, 1989)

IZQUIERDO, Antonio. La immigración en España 1980-1990 (Madrid: Ministerio de Trabajo y Seguridad Social, 1992), 257 pp.

IzQUIERDO, Antonio. La immigración inesperada (Madrid: Trotta, 1996).

KHADER, Bichara. L' Europe et le grand Maghreb (Lovaina: Louvain-la-Neuve, 1992), $364 \mathrm{pp}$.

KRTT, Mary M, Lin LEAN LIM, y Hania ZtOTNIK, eds. Intermational Migration Systems: A Global Approach (Nueva York: Oxford University Press, 1992), 338 pp.

KRTZ, Mary M, Hania ZloTNK. . Global interactions: Migration systems, processes, and policies. pp. 1-16 en Mary M Kritz, Lin Lean Lim, y Hania Zlotnik, eds. International Migration Systems: A Global Approach (Nueva York: Oxford University Press, 1992), $338 \mathrm{pp}$.

LACOMBA, Joan. Sociedad y política en el Magreb (Madrid-Valencia: Universidad de Valencia, 1997), $172 \mathrm{pp}$.

LJVI-BACCI, Massimo. Inmigración y desarrollo: Comparación entre Europa y América (Barcelona: Fundación Paulino Torras Domènech, 1991), 41 pp.

LJV-BACCI, Massimo. South-north migration: A comparative approach to North American and European experiences. pp. 37-46 en OECD. The Changing Course of Intermational Migration (París: OECD, 1993), 264 pp.

LOPEZ GarCía, Bernabé. Política y movimientos sociales en el Magreb (Madrid: CIS-Siglo XXI, 1989), $204 \mathrm{pp}$.

LUCAS, Javier de. Puertas que se cierran (Barcelona: Icaria, 1996), 116 pp.

MaRTiNeLLO, M. Italy: the late discovery of immigration, pp. 195-218 en Dietrich Thränhardt Europe: A New Immigration Continent (Hamburgo: Lit, 1992).

MASSEY, Douglas S. Economic development and international migration in comparative perspective Population and Development Review, vol. 14, n² 3 (1988), pp. 383-413.

MaSSEY, Douglas S., Joaquín ARANGo'; Graeme Hugo, Ali Kouaouci, Adela Pellegrino, J. Edward Taylor. Theories of international migration: A review and appraisal, Population and Development Review, vol. 19, $\mathrm{n}^{\otimes} 3$ (1993), pp. 431-466.

Massey, Douglas S., Joaquín Arango, Graeme Hugo, Ali Kouaoucl, Adela Pellegrino, J. Edward TAYLOR. An evaluation of international migration theory: The North American case. Population and Development Review, vol. 20, $n^{2} 4$ (1994), pp. 699-751.

MiguEl, Jesús M. de. El mito de la saciedad organizada (Barcelona: Peninsula, 1990), $170 \mathrm{pp}$.

Miguel, Jesús M. DE, Jordi Cais, Emilio J. CastLla y Juan SALCEDO. Demographic Imbalances Between Countries of the Mediterranean Basin (Estrasburgo: CDPO del European Council, 1993), 66 pp. 
Montobles Pereira, Juan, Bemabé Lopez García, y Domingo del Pino. Explosión demográfica, empleo, y trabajadores emigrantes en el Mediterráno Occidental (Granada: Universidad de Granada, 1993).

NAIIR, Sami. .Desarrollo e inmigración: Una relación compleja• pp. 437-442 en Enrique Viaña Remis y Miguel Hernando de Larramendi, eds. Cooperación cultural en el occidente mediterráneo (Bilbao: Fundación BBV Documenta, 1995), 545 pp.

Nsour, Sahle M. et al. The Path to Convertibility and Growth: The Tunisian Experience (Washington DC: International Monetary Fund, 1993), 25 pp.

Nsourd, Sahle M. et al. Resilience and Growth Through Sustained Adjustment: The Moroccan Experience (Washington DC: Intemational Monetary Fund, 1995), 29 pp.

OECD. The Future of Migration (Paris: OECD, 1987).

OECD. Migration, the Demographic Aspects (Paris: OECD, 1991).

OECD. The Changing Course of International Migration (Paris: OECD, 1993), 264.pp.

OECD. Migration and Development (París: OECD, 1994), 334 pp.

Papademetrou, Demetrios G. Aigration and development: The unsettled relationship. pp. 259-294 en Sergio Diaz-Briquets, y Sidney Weintraub. Determinants of Emigration from Mexico, Central America, and de Caribbean (San Francisco: Westview Press, $1991), 356 \mathrm{pp}$.

Parliamentary Assembly. Report on Demographic Imbalances Between the Countries of the Mediterranean Basin (Doc. 6462, 27 junio 1991). Investigadores: Mota Torres (Portugal), y Vázquez (España)

Parliamentary Assembly Recommendation 1164 (91) on demograpbic imbalances between the countries of the Mediterranean basin, 43 Sesión Ordinaria, 23 de septiembre de 1991. Dividido en 12 puntos, 2 pp. Ver también Recommendation 1148 (91).

PASS, Asesoría de Programas de Servicios Sociales. Mapa de inmigración extranjera en situación imregular (Madrid: Ministerio de Trabajo y Seguridad Social, 1992).

PIORE, Michael. Birds of Passage: Migrant Labour and Industrial Societies (Cambridge: Cambridge University Press, 1979).

PORTES, Alejandro. Migration and underdevelopment. Politics and Society, vol. $8, \mathrm{n}^{9} 1$ (1978) pp. $1-48$.

PORTES, Alejandro. Unautorized immigration and immigration reform: Present trends and prospects. pp. 75-95 en Sergio Diaz-BriqueTs y Sidney WeinTRAuB. Determinants of Emigration from Mexico, Central America, and de Caribbean (San Francisco: Westview Press, 1991), $356 \mathrm{pp}$

PORTES, Alejandro y József BOROOCZ. .Contemporary inmigration: Theoretical perspectives on its determinants and modes of incorporation. International Migration Review, vol. $23, n^{2} .3(1989)$, pp. 606-629.

PORTES, Alejandro y John WaLTON. Labor, Class, and the International System (Nueva York: Academic Press, 1981), 223 pp.

PraDA, Miguel Ángel de. España, de país de emigración a país de inmigración. pp. 209-241 en Maria Ángeles Roque, Movimientos bumanos en el Mediterráneo occidental (Barcelona: Generalitat de Catalunya, 1990).

RAMirez GOICOECHEA, Eugenia. Inmigrantes en España: Vidas y experiencias (Madrid: Centro de Investigaciones Sociológicas/Siglo XXI, 1990), 611 pp.

RAVENSTEIN, E. G. .The laws of migration. Joumal of he Royal Statistical Society 48 (1885), p. 198.
RAVENSTEIN, E. G. :The laws of migration. Joumal of be Royal Statistical Society 52 (1889), p. 286.

RICHARDS, Anne. Trade liberalisation and migration flows: Some evidence from developing countries. pp. 153-161 en OECD. Migration and Development (París: OECD, 1994), $334 \mathrm{pp}$.

RoQuE, Maria-Àngels, ed. Identidades y conflicto de valores (Barcelona: Icaria, 1997), $348 \mathrm{pp}$.

SALT, John. The future of international labor migration International Migration Review, vol. 26, n. 4 (1992), pp. 1077-1111.

Salt, John, Ann Singleton, y Jennifer HagarT. Eumpe's Intermational Migrants (Londres: HMSO, 1994), 223 pp.

SETIEN, María Luisa. Indicadores sociales de calidad de vida. Un sistema de medición aplicado al Pais Vasco (Madrid: CIS, 1993), 449 pp.

SOPEMI. Trends in International Migration: Continuous Reporting System of Migration (París: OECD, 1992), 243 pp.

SOPEMI. Trends in International Migration: Continuous Reporting System of Migration (París: OECD, 1993), 197 pp.

SOYSAL, Yasemin N. Limits of Citizenship: Migrants and Postnational Membership in Europe (Chicago: University of Chicago Press, 1994), 244 pp.

TAPINOS, Georges. Can international co-operation be an alternative to the emigration of workers?., pp. 175-190 en OECD. The Changing Course of Intemational Migration (París: OECD, 1993), $264 \mathrm{pp}$.

TAPINOS, Georges. Regional economic integration and its effects on employment and migration. pp. 213-228 en OECD. Migration and Development (París: OECD, 1994), $334 \mathrm{pp}$.

TElTELBauM, Michael S. EEffects of economic development on emigration pressures in sending countries. pp. 161-164 en OECD. The Changing Course of International Migration (París: OECD, 1993), $264 \mathrm{pp}$.

TuRNHAm, David. -Rural development policies and their effects on migration', pp. 201212 en OECD. Migration and Development (París: OECD, 1994), 334 pp.

United Nations: Economic Commission for Europe, Economic Survey of Europe in 1991-1992 (Nueva York: United Nations, 1992).

United Nations. Statistical Yearbook 1993 (Nueva York: United Nations, 1995), 841 pp.

United Nations. Demographic Yearbook 1994 (Nueva York: United Nations, 1996), $1.131 \mathrm{pp}$.

ZLOTNK, Hania. Empirical identification of international migration systems., pp. 19-40 en Mary M Kritz, Lin Lean Lim, y Hania Zlotnik, eds. Intermational Migration Systems: A Global Approach (Nueva York: Oxford University Press, 1992), 338 pp.

ZLOTNIK, Hania. The role of international migration in population equilibrium, $\mathrm{pp}$. $47-53$ en OECD. The Changing Course of International Migration (Paris: OECD, 1993), $264 \mathrm{pp}$.

ZOLBERG, Aristide R. -The next waves: Migration theory for a changing world Intermational Migration Review, vol. 23, n 3 (1989), pp. 403-429.

ZOLBERG, Aristide R. The future of intemational migrations pp. 319-351 en Sergio Diaz-Briquets y Sidney Weivtraub. Determinants of Emigration from Mexico, Central America, and de Caribbean (San Francisco: Westview Press, 1991), 356 pp. 